\title{
Recent Advances in Neonatal Gastroenterology and Neonatal Nutrition
}

\author{
Shripad Rao, Madhur Ravikumara, Gemma McLeod and Karen Simmer \\ Centre for Neonatal Research and Education, The University of Western Australia, \\ Neonatology Clinical Care Unit and the Department of Gastroenterology, \\ King Edward Memorial Hospital and Princess Margaret Hospital, Perth, \\ Australia
}

\section{Introduction}

Nutrition plays an important role in achieving optimal growth and development of the high risk neonate. Recent developments have shown that aggressive parenteral nutrition defined as relatively high amounts of parenteral protein and lipid commencing on the first day of life reduces the incidence of ex-utero growth retardation (EUGR) and associated morbidities.

For preterm infants, early minimal enteral feed and a standardised feeding regime have improved clinical outcomes. Probiotics appear useful in further reducing the incidence of necrotizing enterocolitis (NEC).

Short-gut syndrome is not infrequent after NEC and fish oil lipid emulsions are useful in the prevention and treatment of intestinal failure-associated liver disease (IFALD).

Use of preformed silos has been shown to improve the outcomes of gastroschisis by decreasing the risk of abdominal compartment syndrome and iatrogenic gut ischemia.

Until recently, neonatal haemochromatosis was considered uniformly fatal disease and only curative treatment was liver transplantation. Exchange transfusion and intravenous immunoglobulin therapy are emerging as potentially curative strategies for this condition.

High index of suspicion and early diagnosis and management of malrotation is highly essential to prevent the dreaded complication of volvulus with intestinal gangrene.

The WHO 2006 growth charts are useful in monitoring the subsequent growth term infants and avoid over-diagnosis of growth failure and under-diagnosis of obesity. These growth charts also have the potential of being useful in monitoring the growth of preterm infants after post-conceptional age of 40 weeks.

In this chapter, we have reviewed all these recent advances and potentially better practices which most likely will help improve the outcomes of high risk neonates.

\section{Recent developments in nutrition for preterm infants}

Growth retardation after preterm birth or EUGR is defined as discharge weight less than the $10^{\text {th }}$ percentile of intra-uterine growth expectation. The risk of EUGR increases with 
decreasing gestational age and birth weight. Dusick et al (Dusick et al. 2003) using NICHD network (National Institute of Child and Human Development) reported that nearly 100\% of very low birth weight $(501-1500 \mathrm{~g})$ infants have growth failure at 36 weeks postconceptional age (PCA). They also reported that $40 \%$ were still less than the $10^{\text {th }}$ percentile for weight at 18 months of age.

Impaired growth during and after discharge from hospital is associated with increased neurodevelopmental problem in infancy and early childhood(Latal-Hajnal et al. 2003, Ehrenkranz et al. 2006). Current consensus is that the neonatologists should be focused on improving the early nutrient management of these infants, allowing them to reach an adequate growth rate (at least $18-20 \mathrm{~g} / \mathrm{kg} / \mathrm{d}$ ), thereby avoiding the need of a late un-physiological catchup growth(Fanaro 2010). Hence, nutritional guidelines have been revised with the aim of reducing EUGR and sequalae (Tsang $R$ et al. 2005). The revised nutritional recommendations theoretically should result in body composition similar to a healthy fetus that has less body fat than most preterm infants currently have at term. The new guidelines recommend protein intakes of 3.5 to $4.5 \mathrm{~g} / \mathrm{kg} /$ day and up to $130-150 \mathrm{kcal} / \mathrm{kg} /$ day.

Once EUGR occurs, excessive catch up growth may lead to increased adiposity and insulin resistance and metabolic syndrome later in life (Yeung 2006, Morrison et al. 2010). This has led to a dilemma after discharge: whether to aim for better nutrition to achieve improved neurodevelopmental outcomes, which may come at a cost of early-onset obesity and diabetes (Ong 2007).

A recent randomised trial has shown that catch-up growth if achieved with optimal nutrition may not lead to excessive central adiposity(Cooke et al. 2010). Preterm infants with a GA $<34 \mathrm{wk}$ and a birth weight of $<1750 \mathrm{~g}$ were randomized immediately before hospital discharge to be fed with a nutrient-enriched formula or a standard formula for 6 months. They found that more rapid and more complete "catch-up," was noted in infants fed with the nutrient-enriched formula. This "catch-up" was due to increased fat free mass and fat accretion on the legs rather than central adiposity measured by DEXA.

The results of this RCT provide some reassurance that catch up growth and hence improved neurodevelopmental outcomes may be achievable without paying the price of increased risk of obesity, diabetes and hypertension. Similar studies and long term follow up are desirable to gain further knowledge in this area.

\subsection{Parenteral nutrition}

In extremely preterm infants, at least $1.5 \mathrm{~g} / \mathrm{kg} /$ day of protein is required to prevent negative nitrogen balance and $3.5 \mathrm{~g} / \mathrm{kg} /$ day to achieve positive balance (fetal equivalent) . It has been calculated that if a 26 week gestation infant receives only glucose, he will have a $25 \%$ deficit of body protein by 1 week of age (Dusick et al. 2003). There is evidence from randomised controlled trials that an aggressive nutritional regime in the early weeks can minimise the large protein deficit most ELBW babies incur, and reduce the rate of extra-uterine growth retardation (Wilson et al. 1997, Dinerstein et al. 2006). Starting parenteral nutrition on day 1 and providing at least $3 \mathrm{~g} / \mathrm{kg} /$ day amino acids by day 5 will reduce the incidence of EUGR, improve nitrogen retention and maintain amino acids within the fetal reference range(Poindexter et al. 2006, te Braake et al. 2007). Extremely low birth weight (ELBW) infants require $70 \mathrm{kcal} / \mathrm{kg} / \mathrm{d}$ for basal metabolic rate. Their glucose requirement is $8-12$ 
$\mathrm{mg} / \mathrm{kg} / \mathrm{min}(45-56 \mathrm{cal})$ with the balance of non-protein cal given as intravenous lipid. Early lipid (day 2-4), up to $3 \mathrm{~g} / \mathrm{kg} / \mathrm{d}(27 \mathrm{cal} / \mathrm{kg} / \mathrm{d})$ is well tolerated with no documented adverse effects(Simmer and Rao 2005). The lipid emulsion currently used in Australia is based on soybean oil and is rich in essential fatty acids (EFA, 60\%). Alternative lipid emulsions with a mixture of olive, and soybean oil are available commercially in some countries. Advantages of the new blends include lower EFA content and more alpha tocopherol which may result in improved ability to synthesise longer chain metabolites which are the precursors of eicosanoids, reduced lipid peroxidation and oxidative stress, and attenuation of immunosuppressive effects linked to LA. More recently, fish-oil based emulsions have been introduced to prevent and treat parenteral-nutrition induced cholestasis, and to provide preformed DHA. Lipid emulsions available for neonatal parenteral nutrition are reviewed by Deshpande \& Simmer (2011) (Deshpande and Simmer 2011).

\subsection{Enteral nutrition}

Minimal enteral feeds, even for very immature infants, should be started in the first few days at $5-10 \mathrm{mls} / \mathrm{kg} /$ day of human milk. The earlier that enteral feeds are commenced, the earlier full enteral feeds are achieved. Early full enteral feeds is associated with reduced late onset sepsis with no increase in NEC (Ronnestad et al. 2005, Kennedy et al. 2000). Mother's own milk (MOM) is the feed of choice as benefits include improved intelligence, lower infection rates and less NEC (Vohr et al. 2006, Schanler 2001).

Early milk has higher content of nutritional and immunological factors and should be used first. Freezing the milk will greatly reduce the viral CMV load and therefore risk of CMV transmission from unpasteurised milk. If inadequate MOM available, pasteurised donor human milk (PDHM) is preferred to artificial formula. All human milk will require fortification for preterm infants to meet recommended nutritional intakes for optimal growth. Feeds are usually fortified after full enteral feeds are tolerated because of possibility that the higher osmolality of fortified milk may contribute to NEC. Commercial fortifiers contain protein, energy, calcium, phosphate, sodium, minerals and vitamins and are well tolerated by most preterm infants. If MOM and PDHM are unavailable, preterm infants should be fed preterm formula rather than term formula until discharge, as it is tailored to meet the nutritional needs of preterm infants. There is concern that cows' milk protein is a risk factor for NEC and for allergic disease in childhood (Berg et al. 2010, von Berg et al. 2008) and there are commercial fortifiers and preterm formula available that do not contain intact cows' milk protein.

\subsection{Human Milk Banks (HMBs)}

For preterm infants PDHM reduces the incidence of NEC four fold and improves feed tolerance(Quigley et al. 2007). This may be associated with reduced days of parental nutrition and earlier discharge from hospital. Pasteurisation reduces the protective effects of human milk but feeding PDHM is still associated with a lower incidence of infections than feeding formula.

Most informal HMBs closed in the 1980's due to the discovery that the HIV virus could be transmitted through breastfeeding. Many countries have now re-established human milk banking with comprehensive risk management processes, most HMBs provide PDHM for 
preterm infants while in hospital. In Australia, the HMB runs by the code of good manufacturing practices (blood and tissues) and models risk management on codex HACCP (Hazard Analysis Critical Control Point) requirements(Hartmann et al. 2007). Parental consent for PDHM is obtained by lactation consultants to ensure full support of breastfeeding.

\subsection{High dose supplements}

Long chain polyunsaturated fatty acids (LCPUFA) especially docosahexaenoic acid (DHA) may be important for optimal neurological development of preterm infants. The Cochrane Review of LCPUFA supplementation of formula for preterm infants found that there was little evidence to support a benefit but a suggestion but supplementation was usually low dose as it was aimed at breast milk equivalence (0.2-0.5\% DHA) (Schulzke et al. 2011). Makrides et al (2009) randomised 657 infants < 33 weeks gestation to high dose DHA, (approximately 1\% DHA aimed at in utero supply) by supplementing lactating mothers to increase breast milk DHA (average breast milk levels). Bayley mental developmental index was higher at 18 months (girls only) and there was less developmental delay (all infants) especially in the $<1250 \mathrm{~g}$ subgroup, with high dose DHA supplementation compared with low-moderate dose (0.3\% DHA). (Makrides et al. 2009).

Vitamin A is required for normal lung growth and meta-analysis of clinical trials suggests that Vitamin A supplementation is associated with reduction in death and chronic lung disease in preterm infants. The optimal dose for extremely low birth weight infants $(<1 \mathrm{~kg})$ appears to be 5000 IU IM three times weekly for four weeks (Darlow and Graham 2007). Vitamin A delivery from parenteral nutrition is better if added to lipid emulsion.

Probiotic supplementation of VLBW infants reduces death and NEC (Deshpande et al. 2010). Sourcing a preparation is challenging in most countries. On-line evidence-based guidelines for the use of probiotics in preterm infants are available(Deshpande et al. 2011).

In summary, avoidance of postnatal growth retardation, early parenteral nutrition with fish/olive oil based lipid emulsions, early enteral feeding with human milk, supplementation with DHA, vitamin A and probiotics are potentially best practices to achieve optimal clinical outcomes after preterm birth.

\section{Intrauterine growth restriction}

\subsection{Definition and diagnosis}

Birth weight is determined by gestational age at time of delivery and by fetal growth rate ( 5 $\mathrm{g} / \mathrm{d}$ at $14-15 \mathrm{wk}$ gestation; $10 \mathrm{~g} / \mathrm{d}$ at $20 \mathrm{w}$ gestation; $30-35 \mathrm{~g} / \mathrm{d}$ at $32-34 \mathrm{w}$ gestation) (Williams et al. 1982)) and its classification describes an infant's birth weight relative to a population reference. In statistical terms, small for gestational age (SGA) denotes a birth weight two standard deviations (SD) below the median birth weight for gestational age (GA). Although $<2$ SD below the median approximates the $2.3^{\text {rd }}$ percentile(De Curtis and Rigo 2004), and may be a more relevant cutoff for indicating perinatal risk, neonates with a birth weight below the $10^{\text {th }}$ percentile for GA are commonly classified as SGA. The term SGA is often used synonymously with intrauterine growth restriction (IUGR), largely because of the difficulties associated with diagnosing IUGR. However, the SGA infant population is a heterogeneous group, with some being constitutionally small, without any 
underlying pathology (80-85\%) whilst others have demonstrated IUGR, implying conceptually, that genetically determined growth potential has not been achieved in utero(Breeze and Lees 2007, Levene et al. 2000). Distinction between a healthy small fetus and one with IUGR can be facilitated by ultrasound examination to detect chromosomal abnormality, amniotic fluid volume changes, serial fetal growth symmetry monitoring and Doppler studies. Utilising customised standards for fetal growth and birth weight that adjust for maternal variables of height, weight, parity and ethnic group, may further improve the accurate detection of IUGR(Figueras and Gardosi 2011). The aim of identifying IUGR is to reduce associated perinatal morbidity and mortality, primarily by optimising the timing and mode of delivery of the growth restricted fetus.

\subsection{Incidence and aetiology}

The study of IUGR has been thwarted by ambiguous terminology and a lack of uniform standards and diagnostic criteria. Most recently this ambiguity has been demonstrated by Olsen et al.(2010). These investigators compared new intrauterine growth curves based on US data collected from 391681 racially diverse infants to the commonly used Lubchenco curves(Lubchenco et al. 1963) and found that the SGA classifications differed significantly for each gestational age $(p<0.0001)$, with the Lubchenco curves underestimating the percentage of infants who were SGA. Similarly, Goldenberg et al(1989) compared 13 different standards from different populations and geographic areas and found a discrepancy of more than $500 \mathrm{~g}$ between GA-specific cut-off values used by different investigators to define IUGR. These anomalies affect the accuracy of incidence data. Nevertheless, IUGR is thought to affect $7-15 \%$ of all pregnancies worldwide(Alisi et al. 2011), and a substantial proportion of IUGR fetuses are delivered preterm. IUGR is not a specific disease entity, but rather, is related to medical conditions compromising (i) placental circulation and efficiency (e.g. placental praevia, placental insufficiency and toxaemia of pregnanacy), (ii) fetal growth and development (e.g. chromosomal disorders, congenital malformations, multiple gestations and infection) and/or (iii) maternal health and nutrition (e.g. pregnancy induced hypertension, maternal hypoxia, vascular and renal disease, substance abuse and malnutrition)(Resnik 2002). The timing of the insult determines whether IUGR is symmetrical or asymmetrical, an outcome linked predominantly to the three phases of fetal growth (cellular hyperplasia: first 16 weeks of gestation; concomitant hyperplasia and hypertrophy: 16-32 weeks gestation; and cellular hypertrophy: 32 weeks to term). Early onset IUGR, arising from severe maternal vascular disease, infection (notably TORCH infections: toxoplasmosis, rubella, cytomegalovirus, varicella, HIV) and chromosomal or structural abnormalities such as cardiac and renal conditions, give rise to small infants with hypoplasia, who display symmetrical growth reductions in weight, length and head circumference (no head-sparing effect) and have a normal ponderal index $(\mathrm{PI})\left[\mathrm{PI}=\left(\text { birth weight }(\mathrm{g}) / \text { Length }(\mathrm{cm})^{3}\right)^{*} 100\right.$; normal PI is $\geq 2.41$; low PI is <2.41]. These infants are unable to achieve their genetically determined growth potential. Later onset of IUGR results from utero-placental disorders and maternal factors leading to impaired delivery of oxygen and nutrients from the placenta. These factors come into play at different times and to varying degrees of severity during pregnancy, but generally, later onset IUGR results in asymmetric growth characterized by a relatively greater decrease in abdominal size (subcutaneous fat and liver volume), low PI, and sparing of head and length(Levene et al. 2000) with potential for some catch up growth. 


\subsection{Pathophysiology}

Compared to gestational-age matched peers, those with IUGR are at higher risk of morbidity and mortality(Damodaram et al. 2011), particularly if growth restriction is severe(Vossbeck et al. 2001, Wienerroither et al. 2001) and delivery is very preterm(Bernstein et al. 2000). The fetus chronically deprived of oxygen and substrates is at increased risk of stillbirth, fetal distress, congenital malformation, meconium aspiration, cord compression, premature rupture of membranes and preterm birth. Neonatal death, asphyxia, hypoglycaemia, meconium aspiration syndrome, polycythaemia, hyperviscosity, hypothermia, infection, pulmonary haemorrhage and transient neonatal hpyperglycaemia are anticipated features of the growth-restricted neonate(Damodaram et al. 2011, Levene et al. 2000). The IUGR preterm infant is also at increased risk of developing necrotizing enterocolitis and respiratory distress syndrome(Bernstein et al. 2000), and may demonstrate continued impaired growth and developmental delay(Bhide 2011, Levene et al.. 2000). IUGR is also associated in later life with features of the metabolic syndrome, including insulin resistance, hypertension, impaired glucose tolerance(Barker 2004) and very recently, nonalcoholic fatty liver disease(Alisi et al. 2011). The fetal adaptations to inadequate nutrition and subsequent IUGR that produce these long-term outcomes are incompletely understood but relate to fetal glucose and fuel metabolism. The adaptations have apparent survival value for the fetus by encouraging efficient glucose and energy utilization, by reducing uptake of amino acids for growth, by reducing production of anabolic hormone, and by increasing glucose supply to vital organs. In the short-term, these survival-motivated adaptations result in asymmetrical growth with some head and length sparing but if these adaptive mechanisms are prolonged or if their onset is more easily inducible in later life, the potential may exist for energy uptake beyond metabolic capacity(Thorn et al. 2011). The adverse outcomes of mismatched pre- and postnatal nutrition and catch up growth have been well demonstrated in animal models (Cleal et al. 2007, Ozanne and Hales 2004).

\subsection{Management}

The current treatment for IUGR is delivery and the main considerations need to be timing and mode of delivery, balancing the risk of neonatal morbidity with continued exposure to a stressful intrauterine environment. Careful monitoring of fetal and uteroplacental function with tests such as serial ultrasound scans, Doppler assessment of umbilical flow and cardiac monitoring will assist in determining optimal delivery time. Admission to a special care nursery (SCN) for observation is necessary for the severely growth restricted infant. It is worth noting that the IUGR phenotype includes decreased pancreatic development and insulin secretion capacity, as well as an up-regulated capacity for glucose uptake and a decreased capacity for synthesising protein for growth(Hay 2008). As Hay(2008) suggests, this could mean that equal rates of amino acids infused into a chronically IUGR infant may not translate to the same increase in growth as that observed in the healthy fetus born preterm and further, that attempts to infuse higher rates of intravenous glucose may produce both lactic acidosis and lipogenesis more readily in the IUGR infant than in the healthy preterm infant. Nutrition recommendations that specifically target IUGR preterm infants are lacking. Feeding regimes for IUGR preterm infants are usually similar to those who are appropriately grown, with some caution as feeds are progressed because of increased risk of NEC. Attention should be given to providing adequate nourishment for the 
IUGR preterm infant from birth so that percentiles are at least maintained and so that extrauterine growth is of proportionate composition to that of the age-matched fetus.

\subsection{Future research directions}

Future research should focus on developing nutrition recommendations and feeding strategies specific for IUGR preterm infants.

Further investigation of the quality of catch up growth achieved by asymmetrically grown IUGR preterm infants in response to macronutrient and energy intakes and implications of catch up growth.

Further elucidation of the mechanisms underlying fetal and postnatal adaptation to IUGR and the impact of these adaptations on long-term health.

Standardisation of IUGR definition, diagnostic tools and method of diagnosis.

\section{Growth monitoring of preterm infants during NICU stay and post discharge}

Growth monitoring of preterm neonates is particularly important in the context of evidence that postnatal growth restriction is associated with long term adverse neuro-developmental outcomes (Ehrenkranz et al. 2006, Shah et al. 2006, Casey et al. 2006, Latal-Hajnal et al. 2003). Careful growth monitoring while in, and after discharge from, NICU has the potential to improve long term outcomes.

\subsection{Types of growth curves currently available for use in preterm infants}

A 'standard' chart represents the ideal healthy growth of a population and hence is of prescriptive nature. A 'reference' chart describes the population without making claims about the health of its sample and hence is descriptive in nature. At present, there are no standard growth charts for preterm infants.

\subsection{Intra uterine growth curves}

The American Academy of Pediatrics('American Academy of Pediatrics Committee on Nutrition: Nutritional needs of low-birth-weight infants' 1985) and Canadian Pediatric society('Nutrient needs and feeding of premature infants. Nutrition Committee, Canadian Paediatric Society' 1995) recommend intra uterine growth rates as the ideal growth of preterm infants. There are more than 25 studies reporting on such 'intrauterine growth charts'. These have been best summarized by Karna et al (Karna et al. 2005). Lubchenko 1963(Lubchenco et al. 1963) and Babson/Benda1976 (Babson and Benda 1976) charts are commonly used in many neonatal units around the world. Fenton et al(Fenton 2003) updated the Babson and Benda growth curves to develop contemporary intrauterine growth curves'. Using preset criteria, three recent large population based surveys of birth weight for gestational age were identified. The Canadian study by Kramer(Kramer et al. 2001) which had a sample size of 676,605 infants delivered between 22 to 43 weeks was used for updating the intrauterine weight section. Two large studies, one from Sweden(Niklasson et al. 1991) and one from Australia(Beeby et al. 1996) were used to update the intrauterine head circumference and length section. The data were averaged together using a weighted 
average based on total sample size to derive the $3^{\text {rd }}, 10^{\text {th }}, 50^{\text {th }}, 95^{\text {th }}$ and $97^{\text {th }}$ percentiles and create one growth chart. CDC 2000 growth charts were used to generate the growth curves from corrected gestation of 40 weeks onwards.

The Fenton chart appears to be useful in monitoring the growth of preterm infants during their NICU stay till they reach corrected gestation of 40 weeks. It is used by many North American, European and Australian centres. Recently Olsen et al have published new intrauterine growth curves based on United States data(Olsen et al. 2010).

The inherent problem with intrauterine growth charts is that, even though they are called "intrauterine" charts, they are in fact cross sectional data derived from anthropometry measured at birth on preterm infants delivered at various gestations. It is well known that fetuses delivered prematurely may not have reached full growth potential due various maternal/fetal morbidities and hence do not reflect the "ideal" growth. Also, these charts do not take into consideration, the normal $5-8 \%$ weight loss that occurs in healthy preterm infants in the first week of life.

\section{3 'Fetal growth curves'}

Strictly speaking, only charts derived from longitudinal studies should be called growth charts, growth being a process extended over time(Bertino et al. 2007). Hence it may appear logical that ideal 'intrauterine growth charts' should be derived from serial and longitudinal assessment of physical parameters of weight, length and head circumference using fetal ultrasound technique(Johnsen et al. 2006). However, the drawback of this method is that fetal ultrasound is not very accurate in predicting the fetal weight. A systematic review(Chauhan et al. 2005) which analysed data from 58 articles over 28 years found wide variability in diagnostic accuracy of ultrasound examination in predicting the fetal weight. Another systematic review(Dudley 2005) concluded that the accuracy of estimated fetal weight using fetal ultrasound is compromised by large intra- and inter-observer variability. Also, maternal morbidities can result in fetal growth restriction, which in turn can result in non- ideal growth charts. In view of such limitations, fetal weight curves derived from the currently available ultrasound technology may not be appropriate for use as ideal postnatal growth of preterm infants.

\subsection{Reference' Growth charts}

Many reference charts that describe the actual longitudinal growth of preterm infants during the course of their stay in the NICU have been published (Diekmann et al. 2005, Bertino et al. 2006). If these reference charts are used to monitor the ongoing growth of preterm infants, extra-uterine growth retardation would be considered as normal. Hence they may not be ideal for monitoring the growth of preterm infants. However, these charts give an idea of what can be achieved with the available resources and limits set by the morbidities of prematurity and can be used compare the growth of preterm infants between different units.

\subsection{A note of caution regarding the use of intra uterine growth charts}

Intra uterine growth charts may appear idealistic goals, but one needs to decide if it is really feasible and safe to attain those parameters. Attempts to promote physical growth by 
aggressive enteral and parenteral nutrition have the potential to harm the sick preterm infant. Rapid increase in enteral feeding is a known risk factor for NEC (Berseth et al. 2003). In ELBW infants, high fluid intake associated with less weight loss during the first 10 days of life is associated with an increased risk of death and BPD (Oh et al. 2005, Wadhawan et al. 2007). In addition excessive catch up growth may result in adverse cardiovascular outcomes later in life. Finken et al(Finken et al. 2006) and Euser etal(Euser et al. 2005) found that in subjects born very preterm, rapid weight gain in infancy was associated with a trend towards higher insulin levels at 19 years. They also concluded that rapid weight gain in both infancy and early childhood is a risk factor for adult adiposity and obesity. Similar concerns have been raised by other investigators (Ekelund et al. 2006, Singhal et al. 2007).

\subsection{Growth charts to monitor preterm infants from post-conceptional age of $\mathbf{4 0}$ weeks into early childhood}

Until recently, many countries used the growth charts released by Centers for Disease Control and Prevention (CDC 2000) for monitoring the growth of term infants and children. The same charts are usually used for ongoing growth monitoring of preterm infants after reaching a corrected gestational age of 40 weeks. The inherent problem with such charts is that they represent the actual existing growth patterns instead of recommended standards.

To resolve this problem inherent with 'reference' charts, WHO has recently released new 'Standard' growth charts for term infants and children(WHO 2006). The WHO multicentre growth reference study (MGRS), was conducted between 1997 and 2003 in 6 countries from diverse geographical regions: Brazil, Ghana, India, Norway, Oman and the United States. The study combined a longitudinal follow-up of 882 infants from birth to 24 months with a cross-sectional component of 6669 children aged 18-71 months. The study populations lived in socioeconomic conditions favourable to growth. The individual inclusion criteria for the longitudinal component were: no known health or environmental constraints to growth, mothers willing to follow MGRS feeding recommendations (i.e. exclusive or predominant breastfeeding for at least 4 months, introduction of complementary foods by 6 months of age and continued breastfeeding to at least 12 months of age), no maternal smoking before and after delivery, single-term birth and absence of significant morbidity. The eligibility criteria for the cross-sectional component were the same as those for the longitudinal component with the exception of infant feeding practices. A minimum of 3 months of any breastfeeding was required for participants in the study's cross-sectional component. Weight-for-age, length/height-for-age, weight-for-length/height and body mass index-for-age percentile and Z-score values were generated for boys and girls aged 0-60 months. The pooled sample from the 6 participating countries allowed the development of a truly international reference. The standards explicitly identify breastfeeding as the biological norm and establish the breastfed child as the normative model for growth and development. They also demonstrate that healthy children from around the world who are raised in healthy environments and follow recommended feeding practices have strikingly similar patterns of growth. These charts are recommendations for how children should grow. More than 100 countries including UK, USA, Canada and New Zealand have started using the WHO growth charts for full term infants. The full set of tables and charts are available on the WHO website (www.who.int/childgrowth/en) together with tools such as software and training materials. 
In the absence of other ideal growth charts, it may be reasonable to use these WHO growth charts to monitor the ongoing growth of preterm infants after reaching post-conceptional age of 40 weeks.

\subsection{Future research}

As discussed above, neither "intrauterine growth charts", "fetal growth charts" nor "postnatal growth charts" are suitable for monitoring the growth of preterm infants till they become term. Similarly, CDC 2000 and WHO 2006 growth charts are also not ideal for monitoring the growth of ex-preterm infants.

In order to establish normative growth charts, the Inter Growth 21st study by the International Fetal and Newborn Growth Consortium has commenced ('http:/ /www.intergrowth21.org.uk/' Accessed 18 September, 2011). The study aims to recruit 4500 healthy women aged 18-35, who had regular menstrual cycles and conceived spontaneously and do not have major health issues and practice healthy lifestyles. Study participant women are recruited from 9 countries across five continents. They undergo 6 scans in addition to the initial dating scans. They are scheduled at 5 weekly intervals: 14-18 weeks, 19-23 weeks, 24-28 weeks, 2933weeks, 34-38 weeks and 39-42 weeks. Apart from the additional scans, they receive the standardized antenatal care. Based on expected $9 \%$ rate of prematurity, it is expected that around 360 infants would be born to these mothers (26-37 weeks gestation). Their longitudinal growth will be monitored for 8 months. This would include measuring weight, length and head circumference every 2 weeks for the first eight weeks and then monthly until eight months after birth. Those suffering from death or serious morbidities of prematurity such as NEC will be excluded. This will study will enable the derivation of prescriptive intrauterine growth curves as well as postnatal growth curves from a diverse population across five continents.

In summary:

1. Intra uterine growth curves, even though are not ideal, are recommended by leading professional paediatric organisations. In the absence of better charts, they are to be used for monitoring the growth of preterm infants.

2. Postnatal growth curves describe the actual growth and hence are descriptive rather than prescriptive. They are not suitable for monitoring the growth of preterm infants.

3. The aim when caring for preterm infants is to at least match the growth velocity of published best postnatal growth curves and strive towards reaching ideal growth velocities of intrauterine growth curves.

4. Due to improvements in management of sick preterm infants, the growth of these infants in 1990 and 2000s is different from those of previous years. Hence it is preferable to use the growth curves developed based on preterm infants born after 1990 .

5. The Fenton chart which has updated the Babson and Benda's chart with data from very large sample size of preterm infants born in the last two decades appears to be suitable for monitoring growth of preterm infants during their stay in the neonatal units.

6. Once a post-conceptional age of 40 weeks is reached, the recently released WHO growth curves can be used to monitor their ongoing growth.

7. While aiming for achieving intrauterine growth velocities in postnatal life, one should not lose sight of the potential short term adverse effects of aggressive nutrition and long term adverse effects of excessive catch up growth. 
The currently ongoing "Intergrowth-21st study" has the potential to overcome the deficiencies of all the existing growth curves and will enable the establishment of prescriptive growth curves for monitoring the growth of preterm infants during and beyond their NICU stay into early childhood.

\section{Probiotics for the prevention of necrotizing enterocolitis}

Necrotizing enterocolitis is a devastating condition in preterm and very low birth weight neonates and carries significant mortality and morbidity (Berrington et al. 2011). Survivors of NEC suffer from significant adverse neurodevelopmental outcomes(Schulzke et al. 2007).

The commonly employed strategies for its prevention are standardised feeding regimen, slow initiation and progression of enteral feeds and preferential use of breast milk (Morgan et al. 2011). In spite of these measures, NEC continues to occur and the latest figures suggest that the incidence in extremely low gestational age neonates is around $11 \%$ (Stoll et al. 2010).

Gastro-intestinal colonisation by pathogenic bacteria is one of the important factors in the pathogenesis of necrotising enterocolitis(Claud and Walker 2001).

Probiotics are defined as live microbial supplements that colonise the gut while providing benefits to the host(Millar et al. 2003). Supplementation with probiotic organisms have been shown to replace the pathogenic bacteria from the intestines by the normal healthy flora. This rationale lead to the conduct of randomised controlled trials, majority of which have consistently shown that probiotic supplementation reduces the incidence of severe necrotising enterocolitis ( $\geq$ stage 2 ). Our meta analysis on this subject estimated a significantly lower risk of NEC in the probiotic group (relative risk [RR]: 0.35 [95\% confidence interval (CI): 0.23-0.55]; $P<.00001)$ (Deshpande et al. 2010). We concluded that further placebo controlled RCTs may not be necessary and probiotic supplementation should be offered routinely for all preterm infants. The updated Cochrane review also expressed similar sentiments (Alfaleh et al. 2011). However, others still are skeptical and advocate caution (Soll 2010, Neu and Shuster 2010) while others feel the evidence is enough to warrant routine use (Tarnow-Mordi et al. 2010, Barrington 2011)

Further to this, our group has published evidence based guidelines for the administration of probiotics in preterm infants for those who believe in probiotic supplementation (Deshpande et al. 2011). Our suggestions for the routine administration of probiotics for preterm infants ( $\leq 34$ weeks) are as follows:

a. Selection of strains: Combination containing Lactobacillus and at least one Bifidobacterium species is preferable. Lactobacillus GG alone may not be effective. Dose: $3 \times 10^{9}$ organisms per day, preferably in a single dose

b. When to commence: When the neonate is ready for enteral feeds, preferably within first 7 days of life.

c. How long to continue: At least until 35 weeks corrected age, or discharge.

d. When to stop: Stopping the supplementation during an acute illness such as sepsis, NEC or perinatal asphyxia may be safe.

A very important step is to find a good quality product meeting the strict criteria of individual countries' drug administration bodies is essential. 


\section{Neonatal short bowel syndrome}

Short-bowel syndrome (SBS), which results from surgical resection or congenital defect (Goulet and Ruemmele 2006, O'Keefe et al. 2006) is a sub category of intestinal failure. Intestinal failure is defined as intrinsic bowel disease resulting in an inability to sustain growth, hydration and electrolyte homeostasis unless parenteral nutrition is provided. Intestinal failure results from intestinal obstruction, dysmotility, surgical resection, congenital defects, or disease-associated loss of absorption and is characterized by the inability to maintain protein-energy, fluid, electrolyte, or micronutrient balance. The Canadian Association of Pediatric Surgeons defines SBS as the need for parenteral nutrition greater than 42 days after bowel resection or a residual small bowel length of less than $25 \%$ expected for gestational age (Wales et al. 2005). Normal small bowel length increases from $1145 \mathrm{~cm}$ between 19 and 27 weeks of gestation through to $172 \mathrm{~cm}$ between 27 and 35 weeks of gestation to a length of $248 \mathrm{~cm}$ in neonates greater than 35 weeks of gestation (Touloukian and Smith 1983). At 1 year of age, small bowel length is approximately $380 \mathrm{~cm}$ (Touloukian and Smith 1983).

The primary aetiologies of SBS in neonatal population are: Necrotizing enterocolitis, intestinal atresias, gastroschisis, malrotation with volvulus, and Hirschprung's disease that extends into the small bowel(Gutierrez et al. 2011).

The principles of management involve multidisciplinary approach focused on nutritional, pharmacologic, and surgical interventions that is directed to achieve maximal gut adaptation and full enteral nutrition while minimizing the complications of PN therapy.

Providing nutrition parenterally is the essential until the gut adaptation is complete and full enteral feeds are tolerated to maintain growth, hydration and electrolyte homeostasis Adequate Glucose, amino acids, lipids and micronutrients should be administered to optimize growth and development. Generally it is recommended that the amount of glucose not to exceed $18 \mathrm{~g} / \mathrm{kg}$ body weight/day(Koletzko et al. 2008), which is shown to be the maximum rate of glucose utilisation. Excessive glucose infusion is considered to be one of the contributing factor for the development of intestinal failure associated liver disease (IFALD).

Lipids are an important source of energy, essential fatty acids and fat soluble vitamins and an essential component of any parenteral nutrition (PN) regimen. Soya bean based lipid emulsions are the commonly used lipid source in most PN solutions. There is increasing evidence that soya bean based lipid emulsions can result in liver disease due to the proinflammatory nature of the w-6 fatty acids. Fish oil based lipid emulsions are rich in w-3 fatty acids which are anti inflammatory and have been shown to be protective against IFLAD and hence are preferred in patients with SBS, especially in those who are likely to need long term PN support(Fallon et al. 2010, Lilja et al. 2011).

Low serum bicarbonate and sodium levels are common in patients with SBS due to increased fecal or stoma loss. The former may be managed by increasing acetate in the PN or enteral supplementation of sodium bicarbonate as tolerated. An important but often neglected complication is chronic body sodium depletion in babies with short gut. Prolonged sodium losses and inadequate supplementation leads to growth failure in neonates. Serum sodium levels may be maintained in the normal range despite inadequate supplementation due to compensatory hyperaldosteronism. Adequate sodium should be administered in the PN or enterally to maintain urinary sodium of $>30 \mathrm{meq} / 1$ and sodium/potassium ratio of atleast 1 (Kocoshis 2010). 
It is important to commence enteral feeds as soon as feasible to prevent complications of TPN and to enable intestinal growth and adaptation. A recent systematic review found very limited number high quality studies addressing the issue of enteral nutrition in infants and children with SBS (Olieman et al. 2010). Hence most of the recommendations are expert opinions or consensus based:

a. Enteral nutrition should be initiated as soon as possible (ie, a few days after bowel resection). Volumes should be gradually increased by $1 \mathrm{~mL} / \mathrm{hr}$ twice a week. Tolerance of new volumes can be assessed by (a) vomiting (more than three times per day/more than $20 \%$ of their daily enteral intake is extensive and indicates intolerance) and (b) quantity and consistency of stool, $\mathrm{pH}$, and sugar reduction of stool. Enteral feeds could be advanced as long as stool or stomal output is $<2 \mathrm{~mL} / \mathrm{kg} / \mathrm{h}$. Because not all enterally administered calories will be absorbed, PN should not be decreased iso-calorically, especially in the initial stages.

b. Continuous enteral nutrition is the recommended mode of administration as it tends to cause less diarrhoea in patients with SBS.

c. The use of breast milk is recommended. The use of breast milk (BM) has been shown to correlate with shorter PN courses and to promote intestinal adaptation. Beneficial components of BM include high levels of nucleotides, amino acids, and immunologic and growth factors. BM also has anti-infectious properties, and glycoproteins in BM deliver iron to the intestinal epithelium, stimulate proliferation and differentiation of crypt cells, influence brush border enzyme activity, and function as scavengers to prevent free radical-mediated tissue damage.

d. Amino acid-based formulas have been associated with a shorter duration of PNdependence when compared with standard formula and can be used if BM is not tolerated.

e. It is recommended to start oral-feeding as soon as possible. Oral feeding can be alternated with continuous enteral feeding. For example, continuous feeding might be stopped for 1 hour, and replaced by a 1-hour dose per bottle or short times of breast feeding. Solid food should be introduced at the age of 4 to 6 months, in low volumes to prevent diarrhea.

f. Animal studies have shown that administration of colostrums protein concentrate may enhance the intestinal adaptation after massive bowel resection (Nagy et al. 2004).

Neonates with SBS may have significant stool or stomal output that precludes transition to enteral feeds. Analysis of stool or stomal effluent for specific carbohydrate malabsorption (stool reducing substances and chromatography) and microscopy for fat globules will give valuable clues which will help modification of enteral formula in a rational manner. If no mechanical or infectious issues are evident, loperamide may be used to decrease stool or stomal output. Stomal re-feeding is also an effective strategy in patients with a long mucous fistula. Early stoma closure should be considered if significant fluid electrolyte imbalance occur due to high stomal loss and good length of colon is remaining.

\subsection{Predictors of outcome in neonates with SBS}

Eventual independence from PN support in short gut depends on various factors, including the residual length of neonatal small bowel, the health and adaptability of the remaining small bowel, presence of ileocaecal valve (ICV) and of colon. Traditionally a small bowel 
length of $15 \mathrm{~cm}$ in the presence of ICV and $40 \mathrm{~cm}$ in the absence of ICV have been described as minimum essential for survival in patients with short bowel syndrome. $35 \mathrm{~cm}$ of neonatal small bowel is associated with a 50\% probability of weaning from PN (Andorsky et al. 2001).

Recent data suggests that percentage of expected small bowel for age rather than the absolute length may be a better predictor of outcomes (Wales and Christison-Lagay 2010, Diamond et al. 2010). In general, it is accepted that ileum is more adaptable than jejunum. A dilated, dysmotile gut fairs poorly than a healthy residual gut. The importance of viable colon in the survival of neonates and children with SBS is not clear with some studies showing benefit (Quiros-Tejeira et al. 2004) while the others did not (Diamond et al. 2010). The presence of colon is helpful because in patients with SBS, when undigested nutrients reach the colon it may induce changes that allow the colonic mucosa to enhance its capacity of water and electrolyte absorption as well as modifications that allow absorption of nutrients such as short- and medium-chain fatty acids. As more intact nutrients reach the colon, trophic hormones such as enteroglucagon may be stimulated, contributing to the intestinal adaptation process. Premature neonates may be at a distinct advantage with regard to intestinal adaptation (Goday 2009).

The ICV slows the transit time of intestinal contents and prevents reflux of colonic contents and bacteria into the ileum. Resection of the ICV can cause bacterial reflux into the small bowel. The ensuing bacterial overgrowth can deconjugate bile salts, reduce bile salt absorption, and impair gut function. Most studies have identified preservation of the ICV as a favourable indicator of long term adaptation although recent studies have not found the presence of intact ICV to be predictor of final outcomes (Diamond et al. 2010, Spencer et al. 2005). Citrulline is a non-structural amino acid that is primarily synthesized in the intestinal mucosa and hence reflects mucosal mass. Serum Citrulline levels correlate well with intestinal length and the ability to wean from PN. Infants with serum citrulline level persistently $<15 \mathrm{mmol} / \mathrm{L}$ are usually unable to wean from PN (Fitzgibbons et al. 2009). The surgical treatment options for neonatal SBS in some centres include bowel conservation at the time of initial presentation, bowel lengthening operations and intestinal transplantation. However, recent experience suggests that the outcomes for infants and children with severe intestinal failure have improved over time and that neonates with extremely short gut, even as low as $10-20 \mathrm{~cm}$ of small intestine, eventually are able to be weaned off from the parenteral nutrition(Sala et al. 2010, Khalil et al. 2011).

\subsection{Complications of SBS}

Three specific complications are frequently associated with SBS: Intestinal Failure Associated Liver Disease (IFALD), Catheter Associated Blood Stream Infections (CABSI) and bacterial overgrowth. In addition poor growth and development will occur if adequate calories, electrolytes and micronutrients are not provided via PN.

IFALD is a common and potentially life-threatening problem for paediatric patients receiving long-term parenteral nutrition $(\mathrm{PN})$. The incidence increases with the duration of TPN(Buchman 2002) and can be as high as $85 \%$ in neonates receiving TPN for prolonged periods of time. The clinical spectrum of IFALD includes hepatic steatosis, cholestasis, fibrosis, and, ultimately, progression to hepatic cirrhosis with portal hypertension and endstage liver disease. Though the cause of IFALD is multifactorial, the single most important 
factor responsible is lack of enteral feeds. Other contributing factors include prematurity, reduced bile acid pool, CABSIs, chronic endotoxemia, toxic constituents in PN, excess glucose and fat in PN. Lipid emulsions derived from soybean oils have been shown to cause liver injury both in vitro and in vivo in rodent models. Preventative strategies include enteral feeding, weaning of PN, reduced dose lipid emulsions and the early recognition and treatment of sepsis. Recent studies have demonstrated the efficacy of fish-oil based lipid emulsions in the prevention and treatment of IFALD (Lilja et al. 2011, Fallon et al. 2010) and has to be incorporated in routine clinical practice. Transplantation is an option for end-stage liver disease but is associated with significant morbidity and mortality(Nehra et al. 2011).

A systematic review of observational studies concluded that Ursodeoxycholic acid may lead to short-term improvement in biochemical indices, but sample size was very small and the risk of bias very high(San Luis and Btaiche 2007). Based on the limited evidence available, ursodeoxycholic acid (10 mg/ kg/dose twice or 3 times daily) may be tried in infants with IFALD who are able to tolerate some enteral intake.

CABSI can result in the loss of the central venous line, recurrent admissions to the hospital and worsen the existing liver injury. Diagnosis includes blood cultures collected from the central line. Treatment includes administration of antibiotic through the central line. In case of fulminant or resistant infection, the catheter will need to be removed. Preventative strategies include following strict protocols and aseptic precautions during insertion and management of the CVCs. A promising therapy in the prevention of CABSI is the use of ethanol locks(Wales et al. 2011). Ethanol has been demonstrated to have the ability to penetrate biofilms that form on central lines, and no bacteria or fungi have been reported to be resistant to ethanol. A recent retrospective study showed a fourfold reduction in CABSI in the cohort-administered ethanol locks (Jones et al. 2010).

Areas of disordered motility and bowel dilation in patients with SBS offer an ideal environment for abnormal bacterial propagation. The adverse effects of bacterial overgrowth include: abdominal pain, worsening motility, mucosal ulceration with bleeding, deconjugation of bile acids, and the generation of toxic byproducts such as D-lactic acid. Bacterial overgrowth can also potentiate translocation and cause septicemia. The treatment for suspected bacterial overgrowth is the administration of enteral antibiotics in a cyclical fashion. Antibiotics that are commonly used include those effective against anaerobes or Gram-negative organisms(Gutierrez et al. 2011). Systemically non absorbable antibiotics are preferred.

\section{Malrotation and volvulus of the intestines in neonates}

Malrotation is a serious congenital condition wherein the normal process of embryonic gut rotation is arrested or altered. The abnormal rotation usually involves both small and large bowel, within the peritoneal cavity. The most important feature is that the abnormally rotated bowel does not have a normal mesenteric attachment. The mesenteric attachment is frequently short and prone to volvulus when part of the intestine loops around the mesentery and intestines resulting in bowel obstruction and gangrene secondary to occlusion of the branches of the mesenteric artery (Figure 1a and $1 \mathrm{~b}$ ). Volvulus renders the entire bowel at risk of ischemia and necrosis. The intestinal obstruction with congenital malrotation can also result from the congenital fibrous bands (Figure $2 a$ and $2 b$ ). 

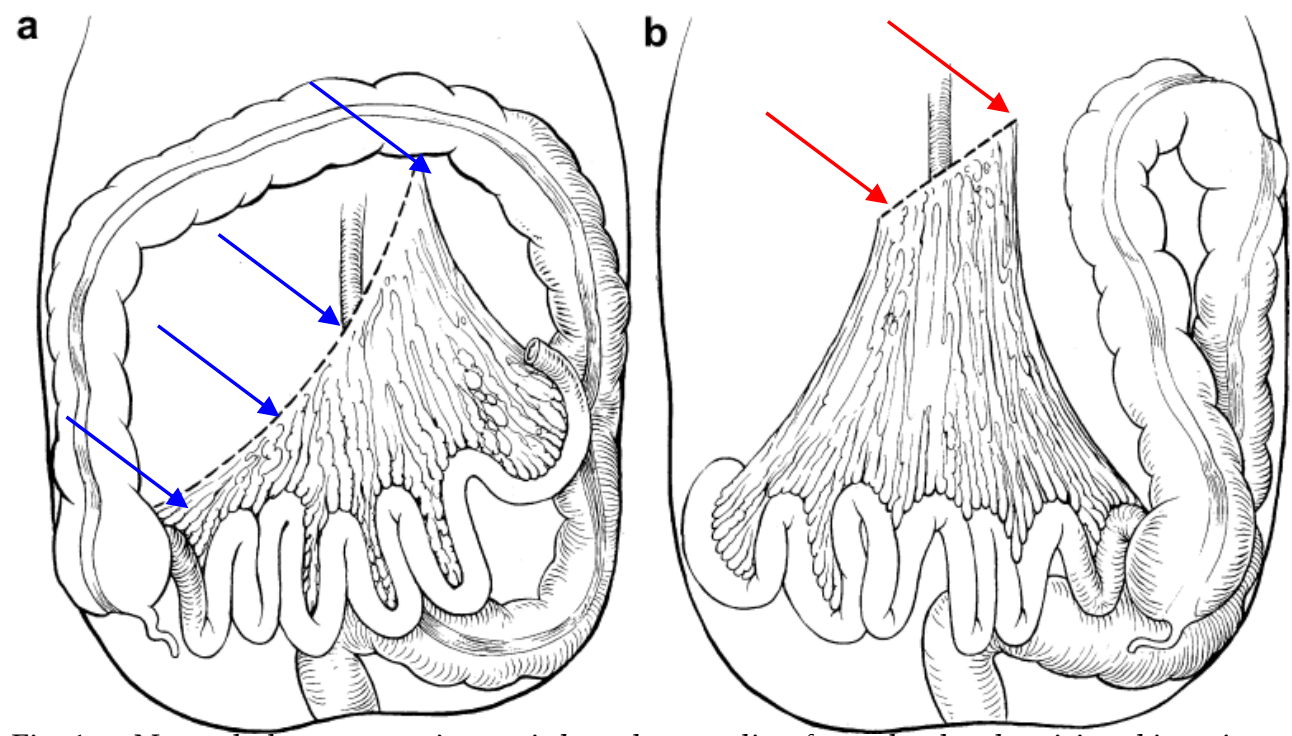

Fig. 1. a. Normal: the mesenteric root is broad, extending from the duodenojejunal junction in the left upper quadrant to the caecum in the right lower quadrant. b. Malrotation: the mesenteric root is narrow, predisposing to volvulus.

a

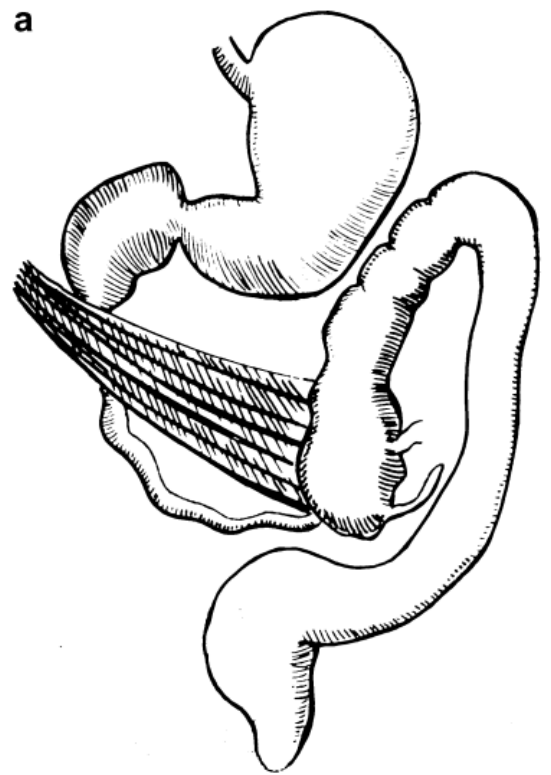

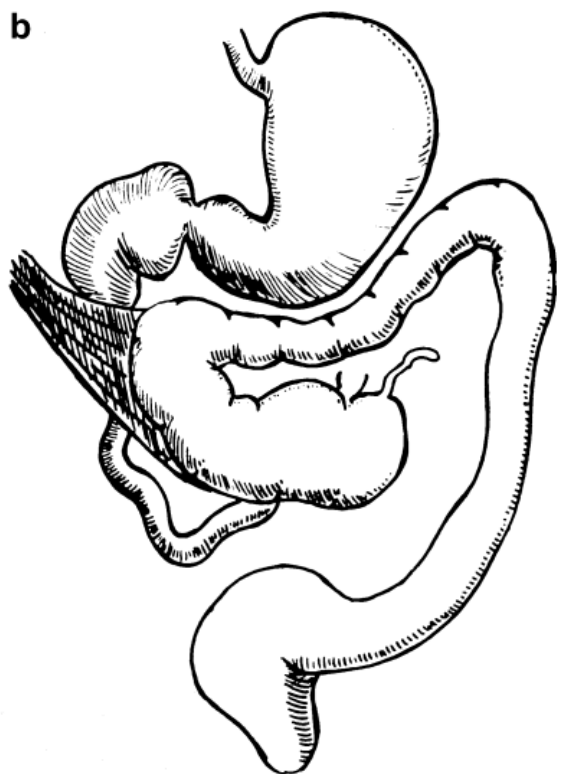

Fig. 2. Ladd's bands extend from the caecum (a) or ascending colon (b) to the right upper quadrant, passing across and variably obstructing the duodenum. 
Clinical features depend on the nature and degree of obstruction (which may be intermittent) and the presence or absence of vascular compromise. Presentation can be asymptomatic but usually results in vomiting often bilious and or abdominal distension. 60 $80 \%$ of patients with malrotation present in the first month of life, mostly in the first week. Bilious vomiting is an important sign of malrotation and must be promptly investigated (William 2007, Kumar 2003)). Even in the absence of bilious vomiting, malrotation/volvulus should be suspected in any neonate presenting with distended abdomen. Even though bilious aspirates can be a sign of dysmotility in extremely premature infants, persistently prolonged bilious aspirates especially lasting more than a week should raise the suspicion of malrotation. Presence of chylous fluid in the inguinal hernia sac during inguinal hernia repair should also alert the surgeons to the possibility of associated malrotation (Zarrouq 2010).

The best imaging test for the diagnosis of malrotation is an upper GI contrast study which will show an abnormal duodenum and duodeno-jejunal (DJ) flexure position (Applegate 2009). It is an emergency investigation and should not be deferred. The normal position of the DJ flexure is to the left of the spine and at the same level or higher than the duodenal bulb. In malrotation, there is no normal duodenal configuration and the proximal small bowel is in the right side of the abdomen (figure $3 a$ and $3 b$ ).

Ultrasound and contrast enema may provide additional information but are not sufficiently accurate to exclude malrotation (Danse 2007, Chao 2000). Presence of normal lactate levels, blood pressure, urine output, blood gases do not rule out the diagnosis of intestinal gangrene secondary to malrotation/volvulus. Once a diagnosis of malrotation and or volvulus is confirmed, urgent surgical review with a view to laparotomy is indicated. Delay in the diagnosis or laparotomy may lead to ischemic necrosis of the bowel.

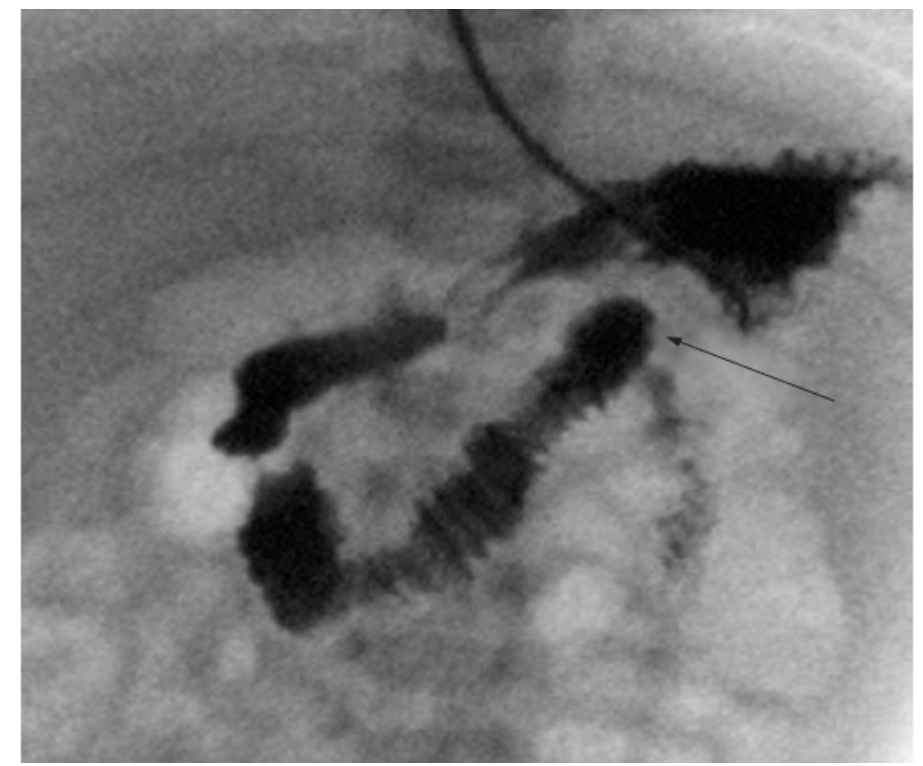

Fig. 3. a. Normal upper gastrointestinal contrast study (AP view) in a neonate with bilious vomiting. Contrast medium was introduced via a nasogastric tube. The duodeno-jejunal flexure is arrowed 


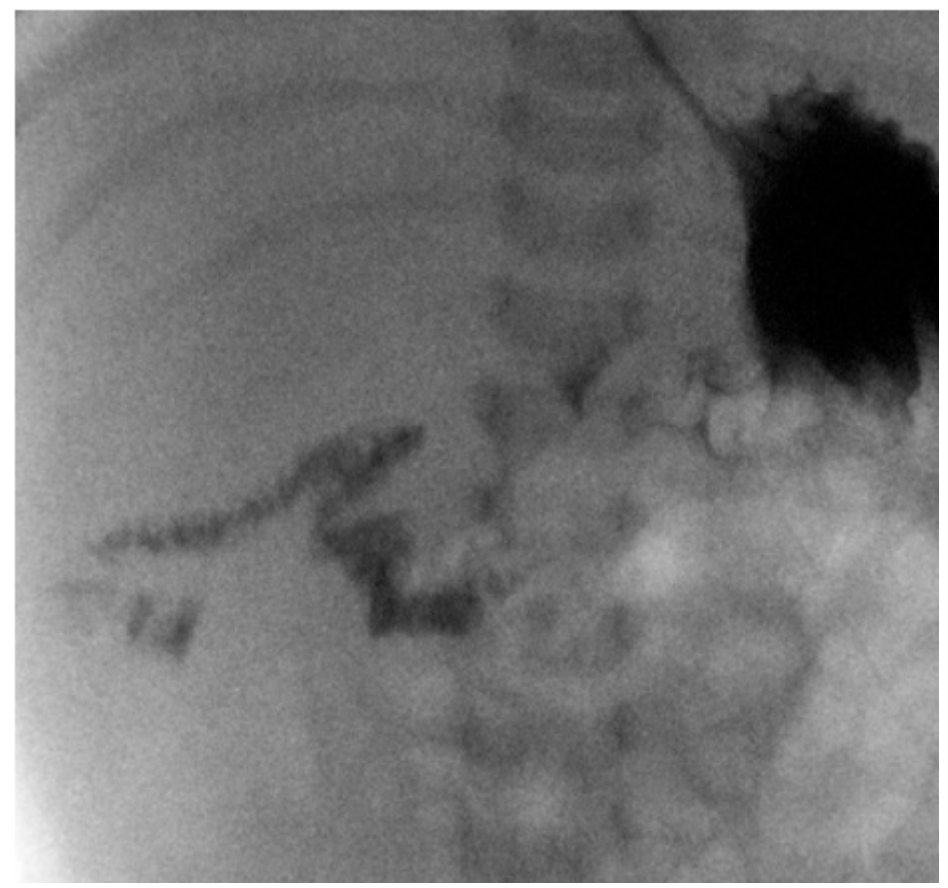

Fig. 3. b. Malrotation. There is no normal duodenal configuration and the proximal small bowel is in the right side of the abdomen.

Treatment is with the standard Ladd's procedure which involves untwisting of the volvulus, division of the Ladd's bands, broadening of the narrow base of the mesentery, division of the adhesions along the small bowel and returning the bowel in a non rotated position. Small bowel is positioned in the right abdomen and the colon in the left abdomen and appendicectomy performed (Millar 2003).

In summary, high index of suspicion, prompt investigation and early laparotomy are essential for the prevention of serious gut related morbidity and mortality secondary to malrotation and volvulus.

\section{Gastroschisis}

Gastroschisis is a congenital defect of the abdominal wall usually located to the right of the umbilical cord, through which abdominal organs herniate. It should be distinguished from omphalocele (or exomphalos), which results from failure of normal return of the bowel to the abdominal cavity during early fetal life. Result in herniated bowel with peritoneal covering and the umbilical cord inserted into the apex of the hernia. Distinguishing these two conditions is very important because they carry different prognoses and the temptation to combine these diseases together as 'anterior abdominal wall defects' should be avoided.

Gastroschisis occurs in up to 5 in every 10000 live births with a sex ratio of approximately 1 . Recent epidemiological surveillance data have shown a 10-20-fold increase in the overall 
incidence of gastroschisis in all age groups over the past two decades (Rasmussen and Frias 2008, Loane et al. 2011, Frolov et al. 2010, Clark et al. 2009).

Pathogenesis of gastroschisis is unknown, but various factors are associated with an increased risk of gastroschisis. They include young maternal age, first pregnancy, low socioeconomic status, lower pre-pregnancy body mass index (BMI), poor maternal diet, disordered family life, use of medications such as aspirin, Ibuprofen, nasal decongestants, maternal infection, smoking, alcohol cocaine, marijuana and genetic polymorphisms (Jones et al. 2009, Mac Bird et al. 2009, Rasmussen and Frias 2008).

More than $90 \%$ patients are diagnosed antenatally using ultrasound (Baird et al. 2011, Garne et al. 2010). The typical sonographic feature is multiple loops of bowel floating freely in the amniotic fluid after the time of normal embryonic return of the intestines to the abdominal cavity (10 weeks of gestation). Typically, the herniated bowel is seen to the right of the umbilical cord insertion, which is inserted normally into the anterior abdominal wall to the left of the herniated bowel. Excluding exomphalos is important in prenatal diagnosis, since exampholos is associated with aneuploidy in up to $40 \%$ of patients, and/or structural abnormalities of other organs.

Ultrasonographic assessment at regular intervals, usually every 2 weeks, is recommended after the diagnosis, to monitor foetal growth and bowel status. Development of polyhydromnios(Japaraj et al. 2003) or of progressive bowel dilatation is considered by some to indicate a poor prognosis (David et al. 2008, Payne et al. 2009) and may warrant early delivery.

Mode of delivery appears not to influence the survival or short term outcomes of gastroschisis and hence caesarean section per se for gastroschisis may not be necessary (Abdel-Latif et al. 2008). Timing of delivery is controversial with some advocating delivery before 37 weeks (Hadidi et al. 2008, Moir et al. 2004, Reigstad et al. 2011). However, since prematurity and low birth weight are associated with increased morbidities in neonates with gastroschisis, many advocate delivery at term in the absence of other obstetric complications or fetal compromise (Ergun et al. 2005, Maramreddy et al. 2009, Logghe et al. 2005).

Following delivery, adequate intravenous fluid resuscitation must be administered as there will be significant evaporative water losses from the exposed bowel. It is important to prevent intestinal distension by gastric decompression with a large bore nasogastric tube. The herniated bowel should be enclosed in a sterile plastic bag or wrapped in warm salinesoaked gauze with plastic wrap. The baby should be positioned on the right side to prevent kinking of the mesentery. The bowel needs be examined for evidence of intestinal atresia, necrosis or perforation.

Various surgical methods have been used to achieve the goal of safe reduction of the herniated viscera back into the abdominal cavity at the earliest possible time (Holland et al. 2010). Options include: (i) Complete primary reduction under general anaesthesia (ii) Complete primary reduction without the use of general anaesthesia (ward reduction) and (iii) application of preformed spring loaded silo followed by gradual reductions over few days.

Primary reduction under general anaesthesia is the traditional and commonly used approach is to reduce the viscera followed by the closure of the fascia and the skin with 
sutures under general anaesthesia (Owen et al. 2010). It will also enable the repair of associated anomalies such as intestinal atresia. Any significant rise in the ventilator requirements during or immediately after the surgical procedure would alert the surgeons to the possibility of abdominal compartment syndrome. In such situations, usually a silo is applied and the viscera gradually reduced over the next few days.

Primary reduction in the ward without the use of general anaesthesia practised this approach with reasonable success (Bianchi et al. 2002, Davies et al. 2005, Cauchi et al. 2006) , whereas the others have found increased complications secondary to abdominal compartment syndrome (Rao et al. 2009, Dolgin et al. 2000). The idea behind this approach is the potential for avoidance of general anaesthesia, avoidance of transfer to a surgical unit and facilitation of early enteral feeds because complete reduction has been achieved very early. This approach was pioneered in the United Kingdom, (Bianchi et al. 2002) but not adopted with enthusiasm (Owen et al. 2010). In Western Australia, this procedure has been abandoned in view of high incidence of complications(Rao et al. 2009).

Staged reduction using Silos is the preferred approach in Western Australia. Preformed spring loaded silos can be placed into the abdominal defect at the bedside to hold the herniated contents. This usually does not require general anaesthesia. Subsequently, the bowel is reduced once or twice daily into the abdominal cavity as the silo is shortened by sequential ligation. This process usually takes between one and 14 days, depending on the condition of the bowel and the infant. Definitive closure is performed once the complete reduction has been achieved. Advantages of this method are the avoidance of iatrogenic intestinal ischemia secondary to abdominal compartment syndrome. Staged reduction using preformed Silos has been found to be safe and effective in many observational studies (Owen et al. 2006, Allotey et al. 2007) and an RCT (Pastor et al. 2008) .

In situations where closure of the abdominal wall defect cannot be achieved with sutures, options are: Using umbilicus as an allograft; Prosthetic materials such as non-absorbable mesh; and biosynthetic absorbable patches such as dura or porcine small intestinal sub mucosa.

Postoperatively, it is important to watch for evidence of abdominal compartment syndrome because of the risk of iatrogenic ischemic necrosis of the bowel. Clinical features are low urine output, poor perfusion, high ventilatory requirements, need for high doses of narcotic analgesia (ischemic gut), metabolic acidosis and elevated lactate levels. Regular clinical review is extremely important and there should be low threshold for re-laparotomy. Some units use intra-gastric or urinary bladder (intra-vesical) pressures as indirect measures of intra-abdominal pressure. Values more than $20 \mathrm{~mm} \mathrm{Hg}$ are thought to indicate the occurrence of this problem (Lacey et al. 1987).

A nasogastric tube should be utilized for gastric decompression in the post operative period. Feeding can commence as early as 2-3 days post operatively once haemodynamic and respiratory stability has been achieved. Early commencement of feeding can facilitate attainment of full enteral feeds soon (Sharp et al. 2000).

Gastroschisis is associated with abnormal intestinal motility and nutrient absorption, both of which gradually improve over time in most patients. Growth should be maintained with appropriate parenteral nutrition. Some infants develop short gut syndrome due to either 
functional dysmotility or anatomically short length of small intestines. Fish oil based lipid emulsions may be beneficial in reducing the severity or prevention of TPN associated cholestasis in such infants (Deshpande and Simmer 2011). Prokinetics such as Erythromycin have not been found to be useful for feed intolerance associated with gastroschisis (Curry et al. 2004).

Survival rate of neonates with gastroschisis is high (93-97\%) (Abdel-Latif et al. 2008, Baird et al. 2011, Minutillo C 2009, Owen et al. 2010). The median time to discharge home range between 23 to 47 days (Minutillo C 2009, Baird et al. 2011), infants with short gut syndrome have very prolonged hospitalisation with the risk of complications of prolonged TPN therapy such as cholestasis and recurrent infections. Limited information available on the physical growth and neurodevelopmental outcomes suggests that treated infants have a good long term prognosis (Minutillo C 2009, Henrich et al. 2008).

In summary, the incidence of Gastroschisis has increased markedly over the past two decades. The majority of infants are diagnosed with early trimester ultrasonography. Primary reduction under general anaesthesia or gradual reduction using preformed silos is preferable and commonly used mode of reducing the contents into the abdominal cavity. A small percentage of cases develop short gut syndrome and need TPN for a protracted length of time. Survival of live born neonates with gastroschisis is very high (>93\%) and limited data suggest that long term outcomes are good.

\section{Neonatal hemochromatosis}

Neonatal hemochromatosis( $\mathrm{NH})$ is defined as severe neonatal liver disease in association with extra-hepatic iron accumulation(Whitington 2007). It is a serious disease and usually leads to death either in utero or in the early neonatal period (mortality rates $70-80 \%$ ). It is the single most common cause of neonatal liver failure(Shanmugam et al. 2011).

The onset of the disease is in utero. Currently it is hypothesised to be an alloimmune process with maternal sensitization to a fetal liver antigen leading to immune injury of the fetal liver and subsequent mishandling and deposition of iron in the liver and extra hepatic tissues(Whitington 2007). Iron deposition (Siderosis) occurs in the liver and extra-hepatic tissues such as pancreas, heart, thyroid and salivary glands. Siderosis explicitly spares the reticulo-endothelial cells(Murray and Kowdley 2001).

The genetics of $\mathrm{NH}$ is unknown but it is not linked to the adult haemochromatosis. $\mathrm{NH}$ has a recurrence risk of approximately $80 \%$ within sibships of same mother but not the father, suggesting the role of a maternal alloimmune factor (Knisely et al. 2003). There are also recent reports of mitochondrial depletion syndromes presenting as $\mathrm{NH}$ (Hanchard et al. 2011).

Infants with NH frequently are preterm or small for gestational age. Pregnancy may be complicated by intrauterine growth retardation, oligohydramnios, placental edema, or polyhydromnios. Affected neonates develop features of liver failure with hypoalbuminemia, hypoglycemia, coagulopathy, low fibrinogen, thrombocytopenia and anaemia. If not present at birth, ascites and hyperbilirubinemia develop within a few days to weeks. Transaminase levels are generally either normal or only moderately elevated suggesting severe intrauterine hepatic damage. 
$\mathrm{NH}$ should be suspected in any sick newborn with evidence of liver disease and in cases of late intrauterine fetal demise.

No single biochemical test is diagnostic of NH. Diagnosis is made after ruling out other causes of liver cell failure in neonates (Murray and Kowdley 2001). This includes various infectious, metabolic, storage and other disorders. In NH, Serum Ferritin levels and Transferrin saturations are raised commonly $95-100 \%$. However, ferritin is an acute phase reactant and elevated levels are seen in many other conditions causing neonatal liver failure and hence, non-diagnostic. The hall mark of NH is extrahepatic siderosis with sparing of reticuloendothelial system. Therefore, in the face of severe coagulopathy, Salivary gland biopsy from the lips or cheek is a safe alternative to liver biopsy and effective way to diagnose $\mathrm{NH}(\mathrm{Smith}$ et al. 2004). The histopathology of the salivary glands shows excessive iron deposition. Other conditions such as echovirus, CMV,HSV, neonatal lupus, tyrosinemia, mitochondrial diseases, rubella, parvovirus and zellweger syndrome may also cause excessive siderosis in extra hepatic organs including salivary glands and hence need to be ruled out by relevant investigations(Murray and Kowdley 2001).

On T2-weighted sequences in MRI scans, tissues with increased iron content have low signal intensity. In $\mathrm{NH}$, the reticulo-endothelial system is spared so that the spleen retains a normal, higher signal intensity compared with affected tissues such as liver, heart and pancreas. Comparing the signal intensity of pancreas, heart and thyroid gland to spleen can be helpful in the diagnosis of NH (Williams et al. 2006, Tsai et al. 2009).

The differential diagnosis of neonatal liver failure include infections, perinatal asphyxia, metabolic conditions like tyrosinemia, galactosemia, Heriditary fructose intolerance, and urea cycle defects, Haemophagocytic Lymphohistiocytosis (HLH), mitochondrial disorders and Congenital disorder of glycosylation.

Supportive management involves administration of Fresh Frozen plasma, cryoprecipitate and vitamin $\mathrm{K}$ to normalise the coagulation abnormalities. Repeated administrations for prolonged periods are to be expected in view of ongoing liver failure.

Cocktail of antioxidants including selenium (3 microgram/ $\mathrm{kg}$ /day orally), $\mathrm{N}$ acetyl-Cysteine (50-100 $\mathrm{mg} / \mathrm{kg} /$ day, intravenously or orally), prostaglandin E1 $(0.4$ microgram $/ \mathrm{kg} / \mathrm{h}$, intravenously, for a maximum of two weeks), Desferoxamine $30 \mathrm{mg} / \mathrm{kg} /$ day, intravenously until the ferritin level falls to $500 \mathrm{ng} / \mathrm{mL}$ ) and Vitamin E (25 IU/ kg/day, orally) have been advocated (Grabhorn et al. 2006), but the results are disappointing (Heffron et al. 2007). Similar to Rand et al (2009), our suggestion is to give oral antioxidants such as vitamin $\mathrm{E}$ and Acetylcysteine and avoid intravenous antioxidants and chelating agents. Liver transplantation is the definitive therapy, but carries a high level of morbidity and mortality (Sundaram et al. 2003).

Recent reports have suggested the beneficial role for the treatment of $\mathrm{NH}$. Double volume exchange transfusion followed by 1-3 doses of intravenous immunoglobulin (1gram $/ \mathrm{kg}$ ) has been shown to significantly improve survival without the need for liver transplantations (Rand et al. 2009). Few authors have reported beneficial outcomes with exchange transfusion alone (Timpani et al. 2007, Nicastro and Iorio 2010, Escolano-Margarit et al. 2010).

$\mathrm{NH}$ is the result of severe fetal liver injury that seems to result from maternal-fetal alloimmunity. Women who have had an infant affected with $\mathrm{NH}$ have approximately $80 \%$ 
probability of recurrence in subsequent pregnancies. Recent studies have shown that weekly administration of IVIG to such pregnant mothers from 18 weeks of gestation till full term results in decreased severity of the disease and improved survival in their offsprings (Whitington and Kelly 2008, Nicholl 2010).

In summary, $\mathrm{NH}$ is a lethal condition and until recently, there was no effective medical therapy. Salivary gland biopsy and MRI of the abdomen are useful investigations in the diagnosis of $\mathrm{NH}$. Recent studies have suggested that $\mathrm{NH}$ is possibly alloimmune disorder. Treatment with IVIG during pregnancy for women who had previous child with NH can prevent the occurrence and severity of $\mathrm{NH}$. Exchange transfusion and IVIG may improve survival without the need for liver transplantation for neonates diagnosed with $\mathrm{NH}$.

\section{References}

Abdel-Latif, M. E., Bolisetty, S., Abeywardana, S. \& Lui, K. (2008) 'Mode of delivery and neonatal survival of infants with gastroschisis in Australia and New Zealand', J Pediatr Surg, 43(9), 1685-90.

Alfaleh, K., Anabrees, J., Bassler, D. and Al-Kharfi, T. (2011) 'Probiotics for prevention of necrotizing enterocolitis in preterm infants', Cochrane database of systematic reviews, (3), CD005496.

Alisi, A., Panera, N., Agostoni, C., \& Nobili, V. (2011). Intrauterine growth retardation and nonalcoholic Fatty liver disease in children. Int J Endocrinol, 2011, 269853. doi: $10.1155 / 2011 / 269853$.

Allotey, J., Davenport, M., Njere, I., Charlesworth, P., Greenough, A., Ade-Ajayi, N. \& Patel, S. (2007) 'Benefit of preformed silos in the management of gastroschisis', Pediatr Surg Int, 23(11), 1065-9.

'American Academy of Pediatrics Committee on Nutrition: Nutritional needs of low-birthweight infants', (1985) Pediatrics, 75(5), 976-86.

Andorsky, D. J., Lund, D. P., Lillehei, C. W., Jaksic, T., Dicanzio, J., Richardson, D. S., Collier, S. B., Lo, C. and Duggan, C. (2001) 'Nutritional and other postoperative management of neonates with short bowel syndrome correlates with clinical outcomes', J Pediatr, 139(1), 27-33.

Applegate, K. E., Anderson, J. M. \& Klatte, E. C. (2006) ‘Intestinal malrotation in children: a problem-solving approach to the upper gastrointestinal series', Radiographics, 26(5), $1485-500$.

Applegate, K.E. (2009) 'Evidence-based diagnosis of malrotation and volvulus', Pediatr Radiol', 39 Suppl, 2:S161-3.

Babson, S. G. and Benda, G. I. (1976) 'Growth graphs for the clinical assessment of infants of varying gestational age', J Pediatr, 89(5), 814-20.

Baird, R., Eeson, G., Safavi, A., Puligandla, P., Laberge, J. M. \& Skarsgard, E. D. (2011) 'Institutional practice and outcome variation in the management of congenital diaphragmatic hernia and gastroschisis in Canada: a report from the Canadian Pediatric Surgery Network', J Pediatr Surg, 46(5), 801-7.

Barker, D. J. (2004). The developmental origins of well-being. Philos Trans R Soc Lond B Biol Sci, 359(1449), 1359-1366. doi: 10.1098/rstb.2004.1518. 
Barrington, K. J. (2011) 'Review: probiotics prevented necrotising enterocolitis and reduced mortality in preterm neonates', Archives of disease in childhood. Education and practice edition.

Beeby, P. J., Bhutap, T. and Taylor, L. K. (1996) 'New South Wales population-based birthweight percentile charts', J Paediatr Child Health, 32(6), 512-8.

Berg, A., Kramer, U., Link, E., Bollrath, C., Heinrich, J., Brockow, I., Koletzko, S., Grubl, A., Filipiak-Pittroff, B., Wichmann, H. E., Bauer, C. P., Reinhardt, D. and Berdel, D. (2010) 'Impact of early feeding on childhood eczema: development after nutritional intervention compared with the natural course - the GINIplus study up to the age of 6 years', Clinical and experimental allergy : journal of the British Society for Allergy and Clinical Immunology, 40(4), 627-36.

Bernstein, I. M., Horbar, J. D., Badger, G. J., Ohlsson, A., \& Golan, A. (2000). Morbidity and mortality among very-low-birth-weight neonates with intrauterine growth restriction. The Vermont Oxford Network. Am J Obstet Gynecol, 182(1 Pt 1), 198-206.

Berrington, J. E., Hearn, R. I., Bythell, M., Wright, C. and Embleton, N. D. (2011) 'Deaths in Preterm Infants: Changing Pathology Over 2 Decades', The Journal of pediatrics.

Berseth, C. L., Bisquera, J. A. and Paje, V. U. (2003) 'Prolonging small feeding volumes early in life decreases the incidence of necrotizing enterocolitis in very low birth weight infants', Pediatrics, 111(3), 529-34.

Bertino, E., Coscia, A., Mombro, M., Boni, L., Rossetti, G., Fabris, C., Spada, E. and Milani, S. (2006) 'Postnatal weight increase and growth velocity of very low birthweight infants', Arch Dis Child Fetal Neonatal Ed, 91(5), F349-56.

Bertino, E., Milani, S., Fabris, C. and De Curtis, M. (2007) 'Neonatal anthropometric charts: what they are, what they are not', Arch Dis Child Fetal Neonatal Ed, 92(1), F7-F10.

Bhide, A. (2011). Fetal growth restriction and developmental delay: current understanding and future possibilities. Ultrasound Obstet Gynecol, 38(3), 243-245. doi: 10.1002/uog.10055.

Bianchi, A., Dickson, A. P. \& Alizai, N. K. (2002) 'Elective delayed midgut reduction-No anesthesia for gastroschisis: Selection and conversion criteria', J Pediatr Surg, 37(9), 1334-6.

Breeze, A. C., \& Lees, C. C. (2007). Prediction and perinatal outcomes of fetal growth restriction. Semin Fetal Neonatal Med, 12(5), 383-397. doi: 10.1016/j.siny.2007.07.002.

Buchman, A. (2002) 'Total parenteral nutrition-associated liver disease', JPEN J Parenter Enteral Nutr, 26(5 Suppl), S43-8.

Casey, P. H., Whiteside-Mansell, L., Barrett, K., Bradley, R. H. and Gargus, R. (2006) 'Impact of prenatal and/or postnatal growth problems in low birth weight preterm infants on school-age outcomes: an 8-year longitudinal evaluation', Pediatrics, 118(3), 107886.

Cauchi, J., Parikh, D. H., Samuel, M. \& Gornall, P. (2006) 'Does gastroschisis reduction require general anesthesia? A comparative analysis', J Pediatr Surg, 41(7), 1294-7.

Chao, H. C., Kong, M. S, Chen, J. Y, Lin, S. J. \& Lin, J. N. (2000) ‘Sonographic features related to volvulus in neonatal intestinal malrotation', J Ultrasound Med, 19(6), 371-6.

Chauhan, S. P., Hendrix, N. W., Magann, E. F., Morrison, J. C., Scardo, J. A. and Berghella, V. (2005) 'A review of sonographic estimate of fetal weight: vagaries of accuracy', J Matern Fetal Neonatal Med, 18(4), 211-20. 
Clark, R. H., Walker, M. W. \& Gauderer, M. W. (2009) 'Prevalence of gastroschisis and associated hospital time continue to rise in neonates who are admitted for intensive care', J Pediatr Surg, 44(6), 1108-12.

Claud, E. C. and Walker, W. A. (2001) 'Hypothesis: inappropriate colonization of the premature intestine can cause neonatal necrotizing enterocolitis', The FASEB journal: official publication of the Federation of American Societies for Experimental Biology, 15(8), 1398-403.

Cleal, J. K., Poore, K. R., Boullin, J. P., Khan, O., Chau, R., Hambidge, O., et al. (2007). Mismatched pre- and postnatal nutrition leads to cardiovascular dysfunction and altered renal function in adulthood. Proc Natl Acad Sci U S A, 104(22), 9529-9533. doi: 0610373104 [pii] 10.1073/pnas.0610373104 [doi].

Cooke, R. J., Griffin, I. J. and McCormick, K. (2010) 'Adiposity is not altered in preterm infants fed with a nutrient-enriched formula after hospital discharge', Pediatric research, 67(6), 660-4.

Curry, J. I., Lander, A. D. \& Stringer, M. D. (2004) 'A multicenter, randomized, double-blind, placebo-controlled trial of the prokinetic agent erythromycin in the postoperative recovery of infants with gastroschisis', J Pediatr Surg, 39(4), 565-9.

Damodaram, M., Story, L., Kulinskaya, E., Rutherford, M., \& Kumar, S. (2011). Early adverse perinatal complications in preterm growth-restricted fetuses. Aust N Z J Obstet Gynaecol, 51(3), 204-209. doi: 10.1111/j.1479-82 8X.2011.01299.x.

Danse, E. M., Kartheuser, A., Paterson, H. M. \& Laterre, P. F. (2009) 'Color Doppler sonography of small bowel wall changes in 21 consecutive cases of acute mesenteric ischemia,' JBR-BTR, 92(4), 202-6.

Darlow, B. A. and Graham, P. J. (2007) 'Vitamin A supplementation to prevent mortality and short and long-term morbidity in very low birthweight infants', Cochrane database of systematic reviews, (4), CD000501.

David, A. L., Tan, A. \& Curry, J. (2008) 'Gastroschisis: sonographic diagnosis, associations, management and outcome', Prenat Diagn, 28(7), 633-44.

Davies, M. W., Kimble, R. M. \& Cartwright, D. W. (2005) 'Gastroschisis: ward reduction compared with traditional reduction under general anesthesia', J Pediatr Surg, 40(3), 523-7.

De Curtis, M., \& Rigo, J. (2004). Extrauterine growth restriction in very-low-birthweight infants. Acta Paediatr, 93, 1563-1568.

Deshpande, G. \& Simmer, K. (2011) 'Lipids for parenteral nutrition in neonates', Curr Opin Clin Nutr Metab Care, 14(2), 145-50.

Deshpande, G. and Simmer, K. (2011) 'Lipids for parenteral nutrition in neonates', Current opinion in clinical nutrition and metabolic care, 14(2), 145-50.

Deshpande, G. C., Rao, S. C., Keil, A. D. and Patole, S. K. (2011) 'Evidence-based guidelines for use of probiotics in preterm neonates', BMC medicine, 9, 92.

Deshpande, G., Rao, S., Patole, S. and Bulsara, M. (2010) 'Updated meta-analysis of probiotics for preventing necrotizing enterocolitis in preterm neonates', Pediatrics, 125(5), 921-30.

Deshpande, G., Rao, S., Patole, S. and Bulsara, M. (2010) 'Updated meta-analysis of probiotics for preventing necrotizing enterocolitis in preterm neonates', Pediatrics, 125(5), 921-30. 
Diamond, I. R., Struijs, M. C., de Silva, N. T. and Wales, P. W. (2010) 'Does the colon play a role in intestinal adaptation in infants with short bowel syndrome? A multiple variable analysis', J Pediatr Surg, 45(5), 975-9.

Diekmann, M., Genzel-Boroviczeny, O., Zoppelli, L. and von Poblotzki, M. (2005) 'Postnatal growth curves for extremely low birth weight infants with early enteral nutrition', Eur J Pediatr, 164(12), 714-23.

Dinerstein, A., Nieto, R. M., Solana, C. L., Perez, G. P., Otheguy, L. E. and Larguia, A. M. (2006) 'Early and aggressive nutritional strategy (parenteral and enteral) decreases postnatal growth failure in very low birth weight infants', Journal of perinatology : official journal of the California Perinatal Association, 26(7), 436-42.

Dolgin, S. E., Midulla, P. \& Shlasko, E. (2000) 'Unsatisfactory experience with 'minimal intervention management' for gastroschisis', J Pediatr Surg, 35(10), 1437-9.

Dudley, N. J. (2005) 'A systematic review of the ultrasound estimation of fetal weight', Ultrasound Obstet Gynecol, 25(1), 80-9.

Dusick, A. M., Poindexter, B. B., Ehrenkranz, R. A. and Lemons, J. A. (2003) 'Growth failure in the preterm infant: can we catch up?', Seminars in perinatology, 27(4), 302-10.

Ehrenkranz, R. A., Dusick, A. M., Vohr, B. R., Wright, L. L., Wrage, L. A. and Poole, W. K. (2006) 'Growth in the neonatal intensive care unit influences neurodevelopmental and growth outcomes of extremely low birth weight infants', Pediatrics, 117(4), 1253-61.

Ehrenkranz, R. A., Dusick, A. M., Vohr, B. R., Wright, L. L., Wrage, L. A. and Poole, W. K. (2006) 'Growth in the neonatal intensive care unit influences neurodevelopmental and growth outcomes of extremely low birth weight infants', Pediatrics, 117(4), 1253-61.

Ekelund, U., Ong, K., Linne, Y., Neovius, M., Brage, S., Dunger, D. B., Wareham, N. J. and Rossner, S. (2006) 'Upward weight percentile crossing in infancy and early childhood independently predicts fat mass in young adults: the Stockholm Weight Development Study (SWEDES)', Am J Clin Nutr, 83(2), 324-30.

Ergun, O., Barksdale, E., Ergun, F. S., Prosen, T., Qureshi, F. G., Reblock, K. R., Ford, H. and Hackam, D. J. (2005) 'The timing of delivery of infants with gastroschisis influences outcome', J Pediatr Surg, 40(2), 424-8.

Escolano-Margarit, M. V., Miras-Baldo, M. J., Parrilla-Roure, M., Rivera-Cuello, M. and Narbona-Lopez, E. (2010) 'Exchange transfusion as a possible therapy for neonatal hemochromatosis', Journal of pediatric gastroenterology and nutrition, 50(5), 566-8.

Euser, A. M., Finken, M. J., Keijzer-Veen, M. G., Hille, E. T., Wit, J. M. and Dekker, F. W. (2005) 'Associations between prenatal and infancy weight gain and BMI, fat mass, and fat distribution in young adulthood: a prospective cohort study in males and females born very preterm', Am J Clin Nutr, 81(2), 480-7.

Fallon, E. M., Le, H. D. and Puder, M. (2010) 'Prevention of parenteral nutrition-associated liver disease: role of omega-3 fish oil', Curr Opin Organ Transplant, 15(3), 334-40.

Fanaro, S. (2010) 'Which is the ideal target for preterm growth?', Minerva pediatrica, 62(3 Suppl 1), 77-82.

Fenton, T. R. (2003) 'A new growth chart for preterm babies: Babson and Benda's chart updated with recent data and a new format', BMC Pediatr, 3, 13. 
Figueras, F., \& Gardosi, J. (2011). Intrauterine growth restriction: new concepts in antenatal surveillance, diagnosis, and management. Am J Obstet Gynecol, 204(4), 288-300. doi: 10.1016/j.ajog.2010.08.055.

Finken, M. J., Keijzer-Veen, M. G., Dekker, F. W., Frolich, M., Hille, E. T., Romijn, J. A. and Wit, J. M. (2006) 'Preterm birth and later insulin resistance: effects of birth weight and postnatal growth in a population based longitudinal study from birth into adult life', Diabetologia, 49(3), 478-85.

'http://www.intergrowth21.org.uk/', (Accessed 18 September, 2011) [online], available: [accessed 18 September, 2011].

Fitzgibbons, S., Ching, Y. A., Valim, C., Zhou, J., Iglesias, J., Duggan, C. and Jaksic, T. (2009) 'Relationship between serum citrulline levels and progression to parenteral nutrition independence in children with short bowel syndrome', J Pediatr Surg, 44(5), 928-32.

Frolov, P., Alali, J. \& Klein, M. D. (2010) 'Clinical risk factors for gastroschisis and omphalocele in humans: a review of the literature', Pediatr Surg Int.

Garne, E., Dolk, H., Loane, M. \& Boyd, P. A. (2010) 'EUROCAT website data on prenatal detection rates of congenital anomalies', J Med Screen, 17(2), 97-8.

Goday, P. S. (2009) 'Short bowel syndrome: how short is too short?', Clin Perinatol, 36(1), 101-10.

Goldenberg, R. L., Cutter, G. R., Hoffman, H. J., Foster, J. M., Nelson, K. G., \& Hauth, J. C. (1989). Intrauterine growth retardation: standards for diagnosis. Am J Obstet Gynecol, 161(2), 271-277.

Goulet, O. and Ruemmele, F. (2006) 'Causes and management of intestinal failure in children', Gastroenterology, 130(2 Suppl 1), S16-28.

Grabhorn, E., Richter, A., Burdelski, M., Rogiers, X. and Ganschow, R. (2006) 'Neonatal hemochromatosis: long-term experience with favorable outcome', Pediatrics, 118(5), 2060-5.

Gutierrez, I. M., Kang, K. H. and Jaksic, T. (2011) 'Neonatal short bowel syndrome', Semin Fetal Neonatal Med, 16(3), 157-63.

Hadidi, A., Subotic, U., Goeppl, M. \& Waag, K. L. (2008) 'Early elective cesarean delivery before 36 weeks vs late spontaneous delivery in infants with gastroschisis', J Pediatr Surg, 43(7), 1342-6.

Hanchard, N. A., Shchelochkov, O. A., Roy, A., Wiszniewska, J., Wang, J., Popek, E. J., Karpen, S., Wong, L. J. and Scaglia, F. (2011) 'Deoxyguanosine kinase deficiency presenting as neonatal hemochromatosis', Mol Genet Metab, 103(3), 262-7.

Hartmann, B. T., Pang, W. W., Keil, A. D., Hartmann, P. E. and Simmer, K. (2007) 'Best practice guidelines for the operation of a donor human milk bank in an Australian NICU', Early human development, 83(10), 667-73.

Hay, W. W., Jr. (2008). Strategies for feeding the preterm infant. Neonatology, 94(4), 245-254. doi: 000151643 [pii] 10.1159/000151643 [doi].

Heffron, T., Pillen, T., Welch, D., Asolati, M., Smallwood, G., Hagedorn, P., Fasola, C., Solis, D., Rodrigues, J., DePaolo, J., Spivey, J., Martinez, E., Henry, S. and Romero, R. (2007) 'Medical and surgical treatment of neonatal hemochromatosis: single center experience', Pediatric transplantation, 11(4), 374-8.

Henrich, K., Huemmer, H. P., Reingruber, B. \& Weber, P. G. (2008) 'Gastroschisis and omphalocele: treatments and long-term outcomes', Pediatr Surg Int, 24(2), 167-73. 
Holland, A. J., Walker, K. \& Badawi, N. (2010) 'Gastroschisis: an update', Pediatr Surg Int, 26(9), 871-8.

Japaraj, R. P., Hockey, R. \& Chan, F. Y. (2003) 'Gastroschisis: can prenatal sonography predict neonatal outcome?', Ultrasound Obstet Gynecol, 21(4), 329-33.

Johnsen, S. L., Rasmussen, S., Wilsgaard, T., Sollien, R. and Kiserud, T. (2006) 'Longitudinal reference ranges for estimated fetal weight', Acta Obstet Gynecol Scand, 85(3), 28697.

Jones, B. A., Hull, M. A., Richardson, D. S., Zurakowski, D., Gura, K., Fitzgibbons, S. C., Duro, D., Lo, C. W., Duggan, C. and Jaksic, T. (2010) 'Efficacy of ethanol locks in reducing central venous catheter infections in pediatric patients with intestinal failure', J Pediatr Surg, 45(6), 1287-93.

Jones, K. L., Benirschke, K. \& Chambers, C. D. (2009) 'Gastroschisis: etiology and developmental pathogenesis', Clin Genet, 75(4), 322-5.

Karna, P., Brooks, K., Muttineni, J. and Karmaus, W. (2005) 'Anthropometric measurements for neonates, 23 to 29 weeks gestation, in the 1990s', Paediatr Perinat Epidemiol, 19(3), 215-26.

Kennedy, K. A., Tyson, J. E. and Chamnanvanakij, S. (2000) 'Rapid versus slow rate of advancement of feedings for promoting growth and preventing necrotizing enterocolitis in parenterally fed low-birth-weight infants', Cochrane database of systematic reviews, (2), CD001241.

Khalil, B. A., Ba'ath, M. E., Aziz, A., Forsythe, L., Gozzini, S., Murphy, F., Carlson, G., Bianchi, A. and Morabito, A. (2011) 'Intestinal Rehabilitation And Bowel Reconstructive Surgery: Improved Outcomes In Children With Short Bowel Syndrome', Journal of pediatric gastroenterology and nutrition.

Knisely, A. S., Mieli-Vergani, G. and Whitington, P. F. (2003) 'Neonatal hemochromatosis', Gastroenterology clinics of North America, 32(3), 877-89, vi-vii.

Kocoshis, S. A. (2010) 'Medical management of pediatric intestinal failure', Semin Pediatr Surg, 19(1), 20-6.

Koletzko, B., Krohn, K., Goulet, O. and Shamir, R. (2008) Paediatric Parenteral nutrition. A practical reference guide, KARGER.

Kramer, M. S., Platt, R. W., Wen, S. W., Joseph, K. S., Allen, A., Abrahamowicz, M., Blondel, B. and Breart, G. (2001) 'A new and improved population-based Canadian reference for birth weight for gestational age', Pediatrics, 108(2), E35.

Kumar, N., Curry, J. I. (2008) 'Bile-stained vomiting in the infant: green is not good!', Arch Dis Child Educ Pract Ed, 93(3):84-6.

Lacey, S. R., Bruce, J., Brooks, S. P., Griswald, J., Ferguson, W., Allen, J. E., Jewett, T. C., Jr., Karp, M. P. \& Cooney, D. R. (1987) 'The relative merits of various methods of indirect measurement of intraabdominal pressure as a guide to closure of abdominal wall defects', Journal of pediatric surgery, 22(12), 1207-11.

Latal-Hajnal, B., von Siebenthal, K., Kovari, H., Bucher, H. U. and Largo, R. H. (2003) 'Postnatal growth in VLBW infants: significant association with neurodevelopmental outcome', The Journal of pediatrics, 143(2), 163-70.

Latal-Hajnal, B., von Siebenthal, K., Kovari, H., Bucher, H. U. and Largo, R. H. (2003) 'Postnatal growth in VLBW infants: significant association with neurodevelopmental outcome', The Journal of pediatrics, 143(2), 163-70. 
Levene, M., Tudehope, D., \& Thearle, M. (2000). Neonatal Medicine (3 ed.). Oxford, UK: Blackwell Publishing Company.

Lilja, H. E., Finkel, Y., Paulsson, M. and Lucas, S. (2011) 'Prevention and reversal of intestinal failure-associated liver disease in premature infants with short bowel syndrome using intravenous fish oil in combination with omega-6/9 lipid emulsions', J Pediatr Surg, 46(7), 1361-7.

Loane, M., Dolk, H., Kelly, A., Teljeur, C., Greenlees, R. \& Densem, J. (2011) 'Paper 4: EUROCAT statistical monitoring: identification and investigation of ten year trends of congenital anomalies in Europe', Birth Defects Res A Clin Mol Teratol, 91 Suppl 1, S31-43.

Logghe, H. L., Mason, G. C., Thornton, J. G. \& Stringer, M. D. (2005) 'A randomized controlled trial of elective preterm delivery of fetuses with gastroschisis', J Pediatr Surg, 40(11), 1726-31.

Lubchenco, L. O., Hansman, C., Dressler, M., \& Boyd, E. (1963). Intrauterine growth as estimated from liveborn birth-weight data at 24 to 42 weeks of gestation. Pediatrics, 32, 793-800.

Mac Bird, T., Robbins, J. M., Druschel, C., Cleves, M. A., Yang, S. \& Hobbs, C. A. (2009) 'Demographic and environmental risk factors for gastroschisis and omphalocele in the National Birth Defects Prevention Study', J Pediatr Surg, 44(8), 1546-51.

Makrides, M., Gibson, R. A., McPhee, A. J., Collins, C. T., Davis, P. G., Doyle, L. W., Simmer, K., Colditz, P. B., Morris, S., Smithers, L. G., Willson, K. and Ryan, P. (2009) 'Neurodevelopmental outcomes of preterm infants fed high-dose docosahexaenoic acid: a randomized controlled trial', JAMA : the journal of the American Medical Association, 301(2), 175-82.

Maramreddy, H., Fisher, J., Slim, M., Lagamma, E. F. \& Parvez, B. (2009) 'Delivery of gastroschisis patients before 37 weeks of gestation is associated with increased morbidities', J Pediatr Surg, 44(7), 1360-6.

Millar, A. J., Rode, H. \& Cywes, S. (2003) 'Malrotation and volvulus in infancy and childhood', Semin Pediatr Surg, 12(4), 229-36.

Millar, M., Wilks, M. and Costeloe, K. (2003) 'Probiotics for preterm infants?', Archives of disease in childhood. Fetal and neonatal edition, 88(5), F354-8.

Minutillo C, P. S., McMichael J, Dickinson JE \& Rao S. C. (2009) 'Neurodevelopmental outcomes of infants with gastroschisis in Western Australia: A retrospective study, translated by Darwin, NT, Australia', Journal of Paediatrics and Child Health, A171.

Moir, C. R., Ramsey, P. S., Ogburn, P. L., Johnson, R. V. \& Ramin, K. D. (2004) 'A prospective trial of elective preterm delivery for fetal gastroschisis', Am J Perinatol, 21(5), 289-94.

Morgan, J. A., Young, L. and McGuire, W. (2011) 'Pathogenesis and prevention of necrotizing enterocolitis', Current opinion in infectious diseases, 24(3), 183-9.

Morrison, J. L., Duffield, J. A., Muhlhausler, B. S., Gentili, S. and McMillen, I. C. (2010) 'Fetal growth restriction, catch-up growth and the early origins of insulin resistance and visceral obesity', Pediatric nephrology, 25(4), 669-77.

Murray, K. F. and Kowdley, K. V. (2001) 'Neonatal hemochromatosis', Pediatrics, 108(4), 960-4.

Nagy, E. S., Paris, M. C., Taylor, R. G., Fuller, P. J., Sourial, M., Justice, F. and Bines, J. E. (2004) 'Colostrum protein concentrate enhances intestinal adaptation after massive small bowel resection in juvenile pigs', J Pediatr Gastroenterol Nutr, 39(5), 487-92. 
Nehra, D., Fallon, E. M. and Puder, M. (2011) 'The Prevention and Treatment of Intestinal Failure-associated Liver Disease in Neonates and Children', Surg Clin North Am, 91(3), 543-63.

Neu, J. and Shuster, J. (2010) 'Nonadministration of routine probiotics unethical--really?', Pediatrics, 126(3), e740-1; author reply e743-5.

Nicastro, E. and Iorio, R. (2010) 'Neonatal hemochromatosis and exchange transfusion: treating the disorder as an alloimmune disease', Journal of pediatric gastroenterology and nutrition, 50(5), 471-2.

Nicholl, M. C. (2010) 'Successful pregnancy outcome with the use of antenatal high-dose intravenous immunoglobulin following previous neonatal death associated with neonatal haemochromatosis', The Australian \& New Zealand journal of obstetrics \& gynaecology, 50(4), 403-5.

Niklasson, A., Ericson, A., Fryer, J. G., Karlberg, J., Lawrence, C. and Karlberg, P. (1991) 'An update of the Swedish reference standards for weight, length and head circumference at birth for given gestational age (1977-1981)', Acta Paediatr Scand, $80(8-9), 756-62$.

'Nutrient needs and feeding of premature infants. Nutrition Committee, Canadian Paediatric Society', (1995) CMAJ, 152(11), 1765-85.

Oh, W., Poindexter, B. B., Perritt, R., Lemons, J. A., Bauer, C. R., Ehrenkranz, R. A., Stoll, B. J., Poole, K. and Wright, L. L. (2005) 'Association between fluid intake and weight loss during the first ten days of life and risk of bronchopulmonary dysplasia in extremely low birth weight infants', J Pediatr, 147(6), 786-90.

O'Keefe, S. J., Buchman, A. L., Fishbein, T. M., Jeejeebhoy, K. N., Jeppesen, P. B. and Shaffer, J. (2006) 'Short bowel syndrome and intestinal failure: consensus definitions and overview', Clinical gastroenterology and hepatology : the official clinical practice journal of the American Gastroenterological Association, 4(1), 6-10.

Olieman, J. F., Penning, C., Ijsselstijn, H., Escher, J. C., Joosten, K. F., Hulst, J. M. and Tibboel, D. (2010) 'Enteral nutrition in children with short-bowel syndrome: current evidence and recommendations for the clinician', J Am Diet Assoc, 110(3), 420-6.

Olsen, I. E., Groveman, S. A., Lawson, M. L., Clark, R. H., \& Zemel, B. S. (2010). New intrauterine growth curves based on United States data. Pediatrics, 125(2), e214-224. doi: $10.1542 /$ peds.2009-0913.

Ong, K. K. (2007) 'Catch-up growth in small for gestational age babies: good or bad?', Current opinion in endocrinology, diabetes, and obesity, 14(1), 30-4.

Owen, A., Marven, S., Jackson, L., Antao, B., Roberts, J., Walker, J. \& Shawis, R. (2006) 'Experience of bedside preformed silo staged reduction and closure for gastroschisis', J Pediatr Surg, 41(11), 1830-5.

Owen, A., Marven, S., Johnson, P., Kurinczuk, J., Spark, P., Draper, E. S., Brocklehurst, P. \& Knight, M. (2010) 'Gastroschisis: a national cohort study to describe contemporary surgical strategies and outcomes', J Pediatr Surg, 45(9), 1808-16.

Ozanne, S. E., \& Hales, C. N. (2004). Lifespan: catch-up growth and obesity in male mice. Nature, 427(6973), 411-412.

Pastor, A. C., Phillips, J. D., Fenton, S. J., Meyers, R. L., Lamm, A. W., Raval, M. V., Lehman, E., Karp, T. B., Wales, P. W. \& Langer, J. C. (2008) 'Routine use of a SILASTIC spring-loaded silo for infants with gastroschisis: a multicenter randomized controlled trial', J Pediatr Surg, 43(10), 1807-12. 
Payne, N. R., Pfleghaar, K., Assel, B., Johnson, A. \& Rich, R. H. (2009) 'Predicting the outcome of newborns with gastroschisis', J Pediatr Surg, 44(5), 918-23.

Poindexter, B. B., Langer, J. C., Dusick, A. M. and Ehrenkranz, R. A. (2006) 'Early provision of parenteral amino acids in extremely low birth weight infants: relation to growth and neurodevelopmental outcome', The Journal of pediatrics, 148(3), 300-305.

Quigley, M. A., Henderson, G., Anthony, M. Y. and McGuire, W. (2007) 'Formula milk versus donor breast milk for feeding preterm or low birth weight infants', Cochrane database of systematic reviews, (4), CD002971.

Quiros-Tejeira, R. E., Ament, M. E., Reyen, L., Herzog, F., Merjanian, M., Olivares-Serrano, N. and Vargas, J. H. (2004) 'Long-term parenteral nutritional support and intestinal adaptation in children with short bowel syndrome: a 25-year experience', J Pediatr, 145(2), 157-63.

Rand, E. B., Karpen, S. J., Kelly, S., Mack, C. L., Malatack, J. J., Sokol, R. J. and Whitington, P. F. (2009) 'Treatment of neonatal hemochromatosis with exchange transfusion and intravenous immunoglobulin', The Journal of pediatrics, 155(4), 566-71.

Rao, S. C., Pirie, S., Minutillo, C., Gollow, I., Dickinson, J. E. \& Jacoby, P. (2009) 'Ward reduction of gastroschisis in a single stage without general anaesthesia may increase the risk of short-term morbidities: Results of a retrospective audit', J Paediatr Child Health.

Rasmussen, S. A. \& Frias, J. L. (2008) 'Non-genetic risk factors for gastroschisis', Am J Med Genet C Semin Med Genet, 148C(3), 199-212.

Reigstad, I., Reigstad, H., Kiserud, T. \& Berstad, T. (2011) 'Preterm elective caesarean section and early enteral feeding in gastroschisis', Acta Paediatr, 100(1), 71-4.

Resnik, R. (2002). Intrauterine growth restriction. Obstet Gynecol, 99(3), 490-496.

Ronnestad, A., Abrahamsen, T. G., Medbo, S., Reigstad, H., Lossius, K., Kaaresen, P. I., Egeland, T., Engelund, I. E., Irgens, L. M. and Markestad, T. (2005) 'Late-onset septicemia in a Norwegian national cohort of extremely premature infants receiving very early full human milk feeding', Pediatrics, 115(3), e269-76.

Sala, D., Chomto, S. and Hill, S. (2010) 'Long-term outcomes of short bowel syndrome requiring long-term/home intravenous nutrition compared in children with gastroschisis and those with volvulus', Transplant Proc, 42(1), 5-8.

San Luis, V. A. and Btaiche, I. F. (2007) 'Ursodiol in patients with parenteral nutritionassociated cholestasis', Ann Pharmacother, 41(11), 1867-72.

Schanler, R. J. (2001) 'The use of human milk for premature infants', Pediatric clinics of North America, 48(1), 207-19.

Schulzke, S. M., Deshpande, G. C. and Patole, S. K. (2007) 'Neurodevelopmental outcomes of very low-birth-weight infants with necrotizing enterocolitis: a systematic review of observational studies', Archives of pediatrics \& adolescent medicine, 161(6), 583-90.

Schulzke, S. M., Patole, S. K. and Simmer, K. (2011) 'Longchain polyunsaturated fatty acid supplementation in preterm infants', Cochrane database of systematic reviews, (2), CD000375.

Shah, P. S., Wong, K. Y., Merko, S., Bishara, R., Dunn, M., Asztalos, E. and Darling, P. B. (2006) 'Postnatal growth failure in preterm infants: ascertainment and relation to long-term outcome', J Perinat Med, 34(6), 484-9. 
Shanmugam, N. P., Bansal, S., Greenough, A., Verma, A. and Dhawan, A. (2011) 'Neonatal liver failure: aetiologies and management--state of the art', Eur J Pediatr, 170(5), 573-81.

Sharp, M., Bulsara, M., Gollow, I. \& Pemberton, P. (2000) 'Gastroschisis: early enteral feeds may improve outcome', J Paediatr Child Health, 36(5), 472-6.

Sices, L., Wilson-Costello, D., Minich, N., Friedman, H. and Hack, M. (2007) 'Postdischarge growth failure among extremely low birth weight infants: Correlates and consequences', Paediatr Child Health, 12(1), 22-8.

Simmer, K. and Rao, S. C. (2005) 'Early introduction of lipids to parenterally-fed preterm infants', Cochrane database of systematic reviews, (2), CD005256.

Singhal, A., Cole, T. J., Fewtrell, M., Kennedy, K., Stephenson, T., Elias-Jones, A. and Lucas, A. (2007) 'Promotion of faster weight gain in infants born small for gestational age: is there an adverse effect on later blood pressure?', Circulation, 115(2), 213-20.

Smith, S. R., Shneider, B. L., Magid, M., Martin, G. and Rothschild, M. (2004) 'Minor salivary gland biopsy in neonatal hemochromatosis', Archives of otolaryngology--head \& neck surgery, 130(6), 760-3.

Soll, R. F. (2010) 'Probiotics: are we ready for routine use?', Pediatrics, 125(5), 1071-2.

Spencer, A. U., Neaga, A., West, B., Safran, J., Brown, P., Btaiche, I., Kuzma-O'Reilly, B. and Teitelbaum, D. H. (2005) 'Pediatric short bowel syndrome: redefining predictors of success', Ann Surg, 242(3), 403-9; discussion 409-12.

Stoll, B. J., Hansen, N. I., Bell, E. F., Shankaran, S., Laptook, A. R., Walsh, M. C., Hale, E. C., Newman, N. S., Schibler, K., Carlo, W. A., Kennedy, K. A., Poindexter, B. B., Finer, N. N., Ehrenkranz, R. A.,

Sundaram, S. S., Alonso, E. M. and Whitington, P. F. (2003) 'Liver transplantation in neonates', Liver transplantation : official publication of the American Association for the Study of Liver Diseases and the International Liver Transplantation Society, 9(8), 783-8.

Tarnow-Mordi, W. O., Wilkinson, D., Trivedi, A. and Brok, J. (2010) 'Probiotics reduce allcause mortality and necrotizing enterocolitis: it is time to change practice', Pediatrics, 125(5), 1068-70.

te Braake, F. W., van den Akker, C. H., Riedijk, M. A. and van Goudoever, J. B. (2007) 'Parenteral amino acid and energy administration to premature infants in early life', Seminars in fetal \& neonatal medicine, 12(1), 11-8.

Thorn, S. R., Rozance, P. J., Brown, L. D., \& Hay, W. W., Jr. (2011). The intrauterine growth restriction phenotype: fetal adaptations and potential implications for later life insulin resistance and diabetes. Semin Reprod Med, 29(3), 225-236. doi: 10.1055/s0031-1275516.

Timpani, G., Foti, F., Nicolo, A., Nicotina, P. A., Nicastro, E. and Iorio, R. (2007) 'Is exchange transfusion a possible treatment for neonatal hemochromatosis?', Journal of hepatology, 47(5), 732-5.

Touloukian, R. J. and Smith, G. J. (1983) 'Normal intestinal length in preterm infants', J Pediatr Surg, 18(6), 720-3.

Tsai, A., Paltiel, H. J., Sena, L. M., Kim, H. B., Fishman, S. J. and Alomari, A. I. (2009) 'Neonatal hemochromatosis and patent ductus venosus: clinical course and diagnostic pitfalls', Pediatric radiology, 39(8), 823-7. 
Tsang R, Uauy R, Koletzko B and Zlotkin, S. (2005) Consensus recommendations; summary of reasonable nutrient intakes for preterm infants. , In: Nutrition of the Preterm Infant. Scientific Basis and Practical Guidelines. Digital Publishing Inc; Cincinnati, Ohio.

Vohr, B. R., Poindexter, B. B., Dusick, A. M., McKinley, L. T., Wright, L. L., Langer, J. C. and Poole, W. K. (2006) 'Beneficial effects of breast milk in the neonatal intensive care unit on the developmental outcome of extremely low birth weight infants at 18 months of age', Pediatrics, 118(1), e115-23.

von Berg, A., Filipiak-Pittroff, B., Kramer, U., Link, E., Bollrath, C., Brockow, I., Koletzko, S., Grubl, A., Heinrich, J., Wichmann, H. E., Bauer, C. P., Reinhardt, D. and Berdel, D. (2008) 'Preventive effect of hydrolyzed infant formulas persists until age 6 years: long-term results from the German Infant Nutritional Intervention Study (GINI)', The Journal of allergy and clinical immunology, 121(6), 1442-7.

Vossbeck, S., de Camargo, O. K., Grab, D., Bode, H., \& Pohlandt, F. (2001). Neonatal and neurodevelopmental outcome in infants born before 30 weeks of gestation with absent or reversed end-diastolic flow velocities in the umbilical artery. Eur J Pediatr, 160(2), 128-134.

Wadhawan, R., Oh, W., Perritt, R., Laptook, A. R., Poole, K., Wright, L. L., Fanaroff, A. A., Duara, S., Stoll, B. J. and Goldberg, R. (2007) 'Association between early postnatal weight loss and death or BPD in small and appropriate for gestational age extremely low-birth-weight infants', J Perinatol, 27(6), 359-64.

Wales, P. W. and Christison-Lagay, E. R. (2010) 'Short bowel syndrome: epidemiology and etiology', Semin Pediatr Surg, 19(1), 3-9.

Wales, P. W., de Silva, N., Kim, J. H., Lecce, L., Sandhu, A. and Moore, A. M. (2005) 'Neonatal short bowel syndrome: a cohort study', J Pediatr Surg, 40(5), 755-62.

Wales, P. W., Kosar, C., Carricato, M., de Silva, N., Lang, K. and Avitzur, Y. (2011) 'Ethanol lock therapy to reduce the incidence of catheter-related bloodstream infections in home parenteral nutrition patients with intestinal failure: preliminary experience', J Pediatr Surg, 46(5), 951-6.

Whitington, P. F. (2007) 'Neonatal hemochromatosis: a congenital alloimmune hepatitis', Seminars in liver disease, 27(3), 243-50.

Whitington, P. F. and Kelly, S. (2008) 'Outcome of pregnancies at risk for neonatal hemochromatosis is improved by treatment with high-dose intravenous immunoglobulin', Pediatrics, 121(6), e1615-21.

WHO (2006) 'WHO Multicentre Growth Reference Study', Acta Paediatr Suppl, 450, 5-101.

Wienerroither, H., Steiner, H., Tomaselli, J., Lobendanz, M., \& Thun-Hohenstein, L. (2001). Intrauterine blood flow and long-term intellectual, neurologic, and social development. Obstet Gynecol, 97(3), 449-453.

Williams, H. (2007) 'Green for danger! Intestinal malrotation and volvulus', Arch Dis Child Educ Pract Ed, 92(3), ep87-91.

Williams, H., McKiernan, P., Kelly, D. and Baumann, U. (2006) 'Magnetic resonance imaging in neonatal hemochromatosis--are we there yet?', Liver transplantation : official publication of the American Association for the Study of Liver Diseases and the International Liver Transplantation Society, 12(11), 1725. 
Williams, R. L., Creasy, R. K., Cunningham, G. C., Hawes, W. E., Norris, F. D., \& Tashiro, M. (1982). Fetal growth and perinatal viability in California. Obstet Gynecol, 59(5), 624632.

Wilson, D. C., Cairns, P., Halliday, H. L., Reid, M., McClure, G. and Dodge, J. A. (1997) 'Randomised controlled trial of an aggressive nutritional regimen in sick very low birthweight infants', Archives of disease in childhood. Fetal and neonatal edition, 77(1), F4-11.

Yeung, M. Y. (2006) 'Postnatal growth, neurodevelopment and altered adiposity after preterm birth--from a clinical nutrition perspective', Acta paediatrica, 95(8), 909-17.

Zarrough, A. E., Srinivasan, S. K. \& Wulkan, M. L. (2010) 'Incidental chylous fluid during hernia repair may be a harbinger of malrotation', J Pediatr Surg, 45(1) E17-8. 
(C) 2012 The Author(s). Licensee IntechOpen. This is an open access article distributed under the terms of the Creative Commons Attribution 3.0 License, which permits unrestricted use, distribution, and reproduction in any medium, provided the original work is properly cited. 